\title{
Renal collecting duct epithelial cells regulate inflammation in tubulointerstitial damage in mice
}

\author{
Katsuhito Fujiu, 1,2 Ichiro Manabe,,1,3 and Ryozo Nagai1,2,3,4 \\ ${ }^{1}$ Department of Cardiovascular Medicine, ${ }^{2}$ Translational Systems Biology and Medicine Initiative, ${ }^{3} \mathrm{Global}$ COE, \\ and ${ }^{4}$ Translational Research Center, the University of Tokyo Graduate School of Medicine, Tokyo, Japan.
}

\begin{abstract}
Renal tubulointerstitial damage is the final common pathway leading from chronic kidney disease to endstage renal disease. Inflammation is clearly involved in tubulointerstitial injury, but it remains unclear how the inflammatory processes are initiated and regulated. Here, we have shown that in the mouse kidney, the transcription factor Krüppel-like factor-5 (KLF5) is mainly expressed in collecting duct epithelial cells and that $\mathrm{Klf5}$ haploinsufficient mice $\left(\mathrm{KlFS}^{+/-}\right.$mice) exhibit ameliorated renal injury in the unilateral ureteral obstruction (UUO) model of tubulointerstitial disease. Additionally, Klf5 haploinsufficiency reduced accumulation of $\mathrm{CD} 11 \mathrm{~b}^{+} \mathrm{F} 4 / 80^{\text {lo }}$ cells, which expressed proinflammatory cytokines and induced apoptosis among renal epithelial cells, phenotypes indicative of M1-type macrophages. By contrast, it increased accumulation of $\mathrm{CD} 11 \mathrm{~b}^{+} \mathrm{F} 4 / 80^{\mathrm{hi}}$ macrophages, which expressed CD206 and CD301 and contributed to fibrosis, in part via TGF- $\beta$ production - phenotypes indicative of M2-type macrophages. Interestingly, KLF5, in concert with C/EBP $\alpha$, was found to induce expression of the chemotactic proteins S100A8 and S100A9, which recruited inflammatory monocytes to the kidneys and promoted their activation into M1-type macrophages. Finally, assessing the effects of bone marrow-specific Klf5 haploinsufficiency or collecting duct- or myeloid cell-specific Klf5 deletion confirmed that collecting duct expression of Klf5 is essential for inflammatory responses to UUO. Taken together, our results demonstrate that the renal collecting duct plays a pivotal role in the initiation and progression of tubulointerstitial inflammation.
\end{abstract}

\section{Introduction}

The incidence of end-stage renal disease is increasing worldwide and represents a growing clinical and economic burden. Regardless of whether renal injury begins in the glomeruli or within the tubulointerstitium, tubulointerstitial damage is a common feature of all chronic progressive renal diseases and is considered to be the final common pathway leading from chronic kidney disease to end-stage renal disease (1-3). In cases of chronic kidney disease, inflammation is a critical mechanism that promotes closely interlinked fibrosis and cellular injury within the tubulointerstitium (4), and macrophages are the predominant infiltrating immune cells mediating that inflammatory process (3). Earlier studies have suggested that proteinuria, renal hypoxia, and/or glomerulus-derived cytokines may induce macrophage recruitment to the kidneys. However, it remains unclear which cell types responds to pathological stimuli and activate inflammatory processes in the kidney, though proximal tubular epithelial cells have been shown to produce the chemokine MCP-1 (3).

Macrophages infiltrating the kidneys produce various proinflammatory cytokines, including TNF- $\alpha$ and IL- $1 \beta$, as well as metalloproteinases (3). Moreover, the finding that blockade of TNF- $\alpha$ and IL- $1 \beta$ suppresses glomerular inflammation and ameliorates renal damage suggests the infiltrating macrophages contribute in some way to the renal injury (5). Macrophage infiltration also often correlates with the degree of renal fibrosis, and depletion of macrophages reduces fibrosis in several disease models, suggesting that macrophages also contribute to fibrosis (6). On

Conflict of interest: The authors have declared that no conflict of interest exists. Citation for this article: J Clin Invest. 2011;121(9):3425-3441. doi:10.1172/JCI57582 the other hand, macrophages that take up apoptotic cells exhibit antiinflammatory properties and may contribute to resolution of inflammation (7). Indeed, hepatic macrophages were shown to be important for resolution of inflammatory scarring (8). Thus, macrophages likely play multiple, and often opposing, roles in kidney disease and repair (6).

Recent studies demonstrating the diversity of macrophage phenotypes and functionality suggest that the activation state of macrophages may determine their pathogenic or reparative roles in kidney disease (9). In vitro studies have shown that Th1 cytokines, alone or in concert with microbial products, elicit classical M1 activation of macrophages, while Th2 cytokines (IL-4 and IL-13) elicit an alternative form of activation designated M2 $(9,10)$. M2 macrophages are thought to suppress immune responses and promote tissue remodeling $(6,9,10)$, though M2 activation is a rather generic term used to describe various forms of macrophage activation other than classic M1. In addition, the diversity of macrophage activation has been established primarily based on in vitro findings (10), and the phenotypes and functions of M2-type macrophages in vivo are still poorly understood. Very recently it was shown that some, but not all, kidney macrophages exhibit surface expression of Ly-6C (11), which means the macrophage population involved in the renal response to injury is a heterogeneous one. However, the specific functions of the different macrophage subsets are not yet clear.

The renal collecting ducts contribute to the control of water and electrolyte balance. Collecting duct epithelial cells express the water channel aquaporin-2 (AQP2) in their apical plasma membrane and AQP3 and AQP4 in their basolateral membrane (12). Water is transported across the collecting duct epithelium 
A

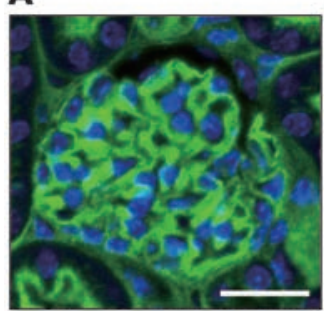

B

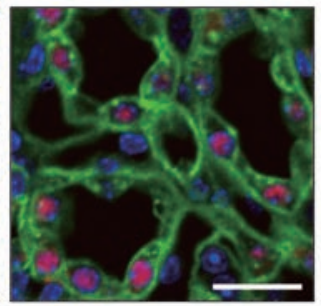

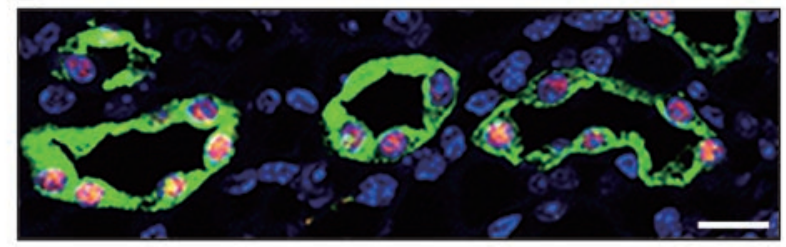

C

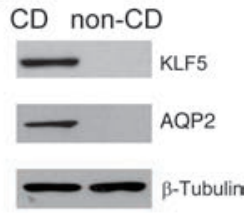

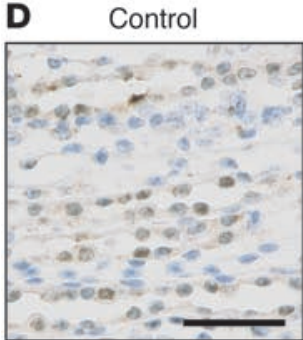

F

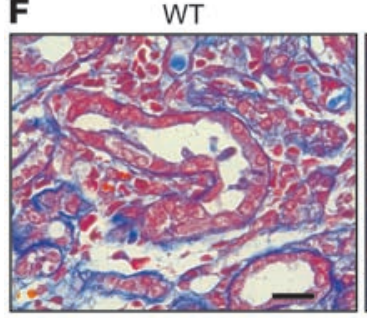

H

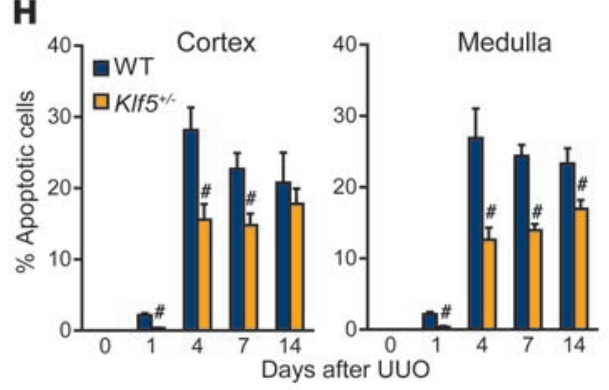

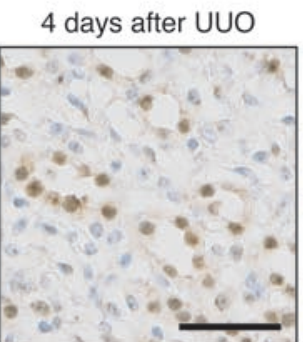

$\mathrm{KIFS}^{+/}$
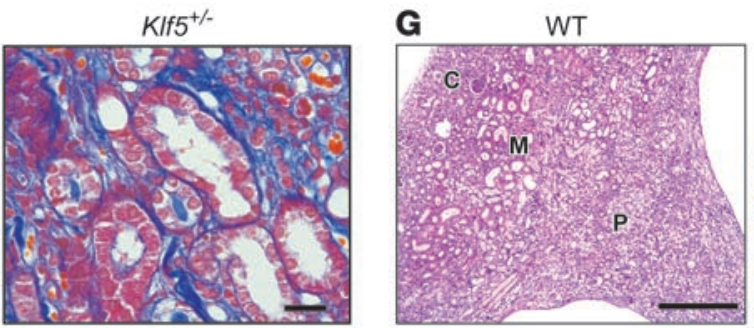

E

WT

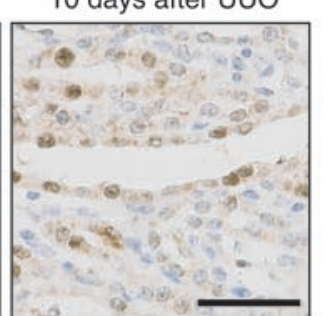

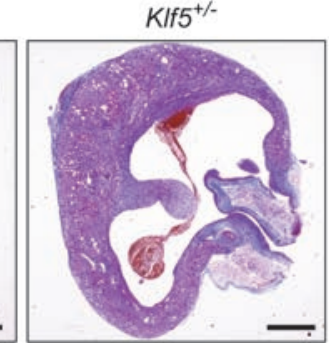

$\mathrm{KIFS}^{+/-}$
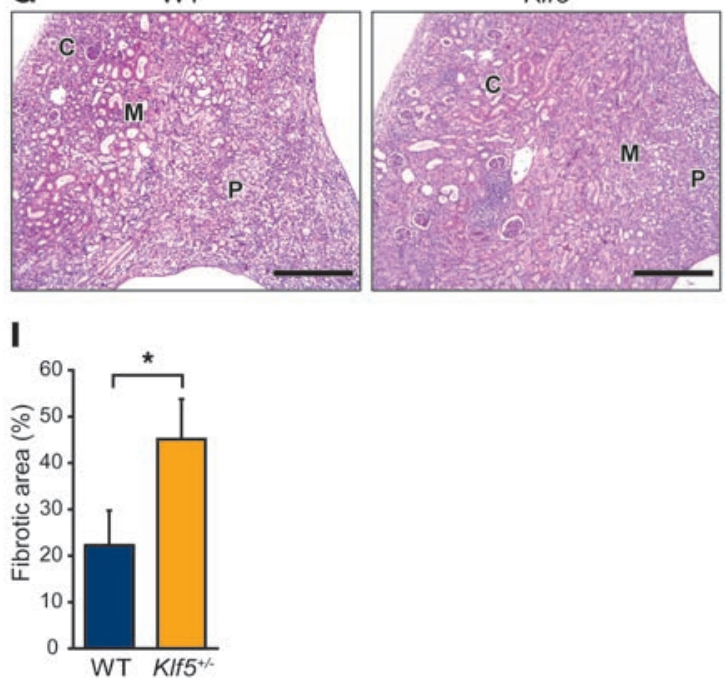

\section{Figure 1}

KLF5 is involved in UUO-induced renal injury. (A) Immunohistochemical staining of KLF5 (red) in mouse kidneys. Left and right panels show portions of the cortex and medulla, respectively. Nuclei and cell membranes were stained using DAPI (blue) and wheat germ agglutinin (green), respectively. Scale bars: $20 \mu \mathrm{m}$. (B) KLF5 expression was confined to AQP2-expressing collecting duct cells in papilla. KLF5 (red), AQP2 (green), and nuclei (blue) are shown. Scale bar: 20 um. (C) Expression of KLF5 protein in the collecting duct. Collecting duct (CD) cells were isolated from kidneys by centrifugal separation. The remaining renal cells were non-CD cells. $\beta$-Tubulin served as a loading control. (D) UUOinduced upregulation of KLF5 in the collecting duct. KLF5 (brown) was detected by immunostaining of sections of medulla under basal conditions (control) and at the indicated times after UUO. Scale bars: $50 \mu \mathrm{m}$. (E-G) Masson's trichrome (E and F) and H\&E (G) staining of wild-type and KIf5+/- kidneys 14 days after UUO. C, cortex; M, medulla; P, papilla. Scale bars: $1 \mathrm{~mm}(\mathbf{E}), 20 \mu \mathrm{m}(\mathbf{F}), 500 \mu \mathrm{m}(\mathbf{G})$. (H) Apoptotic cell fractions in kidneys from wild-type and $K_{1 f 5}+-$ mice at the indicated days after UUO. Apoptotic cells were analyzed by TUNEL staining, as shown in Supplemental Figure 3A. ${ }^{~} P<0.05$ versus wild-type at the same time point. $n=6$. (I) Fibrotic area stained with picrosirius red 14 days after UUO. ${ }^{\star} P<0.05 . n=6$. Representative sections are shown in Supplemental Figure 3C.

through those AQPs. AQP2 is abundantly expressed in the connecting tubule (connecting tubule cells), in the cortical and outer medullary collecting ducts (principal cells), and in the inner medullary collecting duct (IMCD cells) and plays an essential role in urinary concentration. Recent studies have shown that collecting duct cells in culture $(13,14)$ and in the fetal urinary tract obstruction model (15) exhibit a loss in epithelial phenotypes and a concomitant gain in mesenchymal phenotypes through a process often termed "epithelial-mesenchymal transition." This suggests that collecting duct cells are in some way involved in interstitial fibrosis. However, it remains largely unknown whether or how collecting duct cells contribute to tubulointerstitial inflammation.

Members of the Krüppel-like factor (KLF) family of transcription factors are important regulators of development, cellular differentiation, and growth, as well as the pathogenesis of various diseases, including cancer and cardiovascular disease (16). We previously 
A
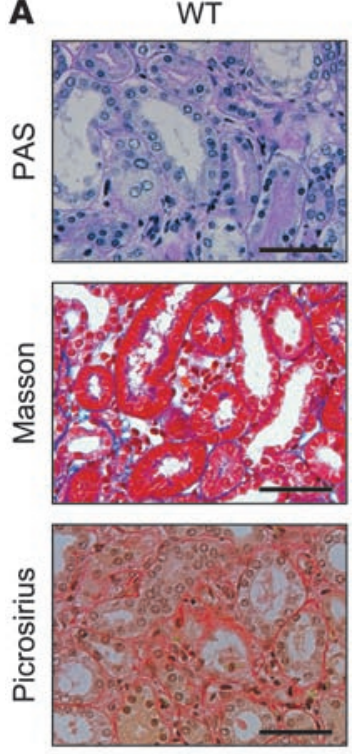
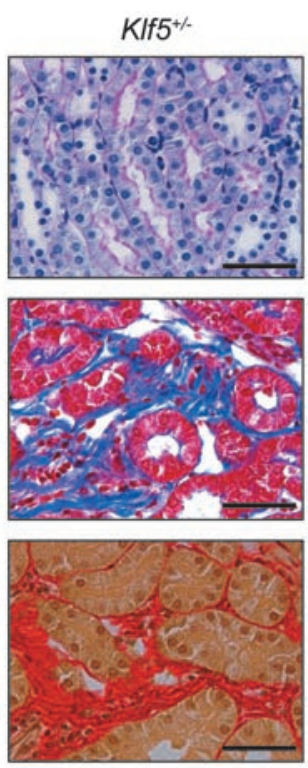

B
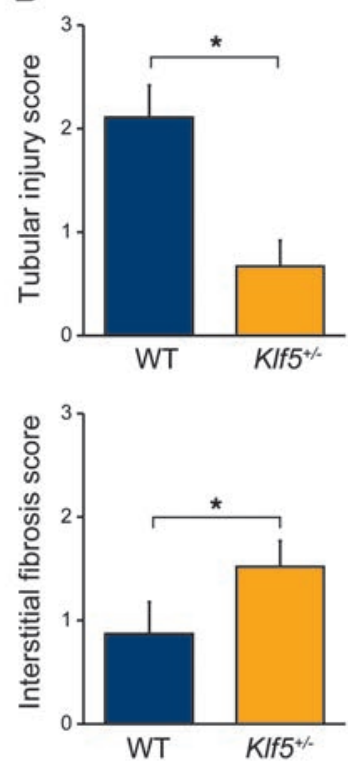

c
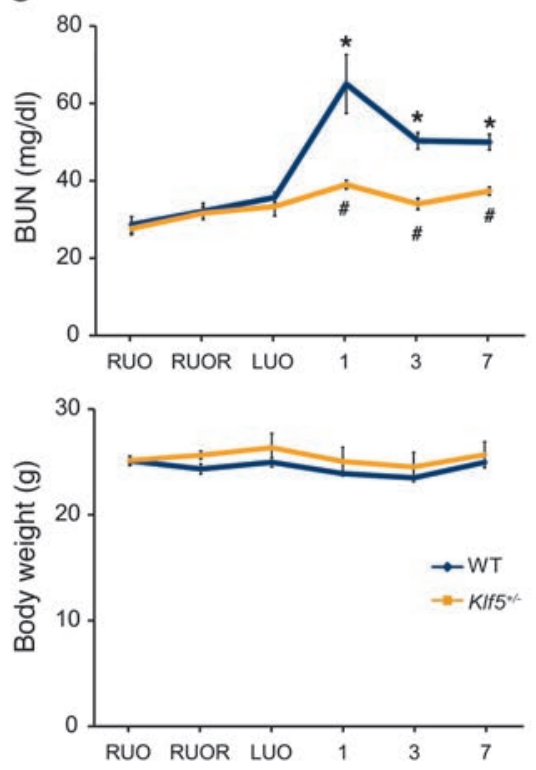

Figure 2

KIf5 haploinsufficiency ameliorated renal dysfunction induced by the reversible UUO. The right ureters of KIf5+- and wild-type mice were transiently obstructed for 3 days; then 7 days after relief of the obstruction, the left ureters were obstructed. (A) Representative PAS, Masson's trichrome, and picrosirius red staining of wild-type and KIf5+/- right kidneys 7 days after left ureter obstruction. Scale bars: $50 \mu \mathrm{m}$. (B) Tubular injury and interstitial fibrosis scores are shown. ${ }^{*} P<0.05$. (C) BUN and body weight were measured prior to right ureteral obstruction (RUO), prior to release of the obstruction (RUOR), prior to left ureteral obstruction (LUO), and on indicated days after LUO. $n=7$ for each group. ${ }^{*} P<0.05$ versus the baseline of the same genotype. ${ }^{\#} P<0.05$ versus wild-type at the same time point.

showed that KLF5 expressed in cardiac fibroblasts is required for the cardiac hypertrophy and fibrosis that develop in response to continuous infusion of angiotensin II and pressure overload (17, 18). KLF5 also plays a central role in arterial wall remodeling $(17,19)$. With these results as background, we were interested in whether KLF5 plays a role in renal tubulointerstitial inflammation and fibrosis. We found that $\mathrm{Klf5}^{+/-}$mice were protected from renal injury induced by unilateral ureteral obstruction (UUO), but showed enhanced fibrosis. Through a combination of in vitro and in vivo analyses, we further show that collecting duct epithelial cells respond to UUO and initiate the accumulation of M1-type macrophages at least in part through KLF5-dependent production of the secretory proteins S100A8 and S100A9. Our findings demonstrate a previously unappreciated function of collecting duct epithelial cells as central regulators of tubulointerstitial inflammatory processes.

\section{Results}

Klf5 is expressed in collecting duct epithelial cells. We first analyzed the distribution of Klf5 expression in the kidney. Immunohistochemical staining showed that, in normal kidneys, KLF5 is expressed in the nuclei of collecting duct epithelial cells, but not in glomeruli or other tubules (Figure 1A). Consistent with this finding, expression of KLF5 was restricted to cells also expressing AQP2, which is known to be specifically expressed in collecting duct epithelial cells (ref. 20, Figure 1B, and Supplemental Figure 1A; supplemental material available online with this article; doi:10.1172/ JCI57582DS1). The collecting duct epithelial cell-specific expression of KLF5 was still further confirmed by its presence in collecting duct cells isolated from kidneys and its absence in non-collecting duct cells (Figure 1C and Supplemental Figure 1B).
Klf5 haploinsufficiency ameliorates renal injury and dysfunction induced by UUO. We next employed the UUO model of tubulointerstitial damage to analyze the role of KLF5 in renal injury (21). We found that UUO increased KLF5 expression in renal collecting duct cells (Figure 1D and Supplemental Figure 1C). Expression of Klf5 mRNA was readily detected in collecting duct cells, but was barely detectable in $\mathrm{CD} 11 \mathrm{~b}^{+} \mathrm{F} 4 / 80^{+}$(monocytes/macrophages), $\mathrm{CD} 1^{+}$(endothelial cells), or $\alpha-\mathrm{SMA}^{+}$(myofibroblasts, mesangial cells, and smooth muscle cells) cells sorted from kidneys (Supplemental Figure 1C). Upon immunohistochemical staining, KLF5 was detected only in collecting duct cells in sections of normal and day 4 UUO kidneys; a few interstitial cells also stained positive for KLF5 in sections of day 10 UUO kidneys (Figure 1D). These results indicate that high-level Klf5 expression is largely limited to collecting duct cells.

Under physiological conditions, Klf5 $5^{+/-}$mice did not exhibit renal dysfunction or pathological changes (Supplemental Figure $2 \mathrm{~A}$ and Supplemental Table 1). However, when $\mathrm{Klf5}^{+/-}$mice were subjected to UUO, they exhibited less renal structural destruction than wild-type mice, as indicated by amelioration of tubular dilation and atrophy, tubular epithelial cell sloughing, and tubular basement membrane thickening (Figure 1, E-G, and Supplemental Figure 2B). Consequently, kidney weight loss and tubular injury score were significantly lower in $\mathrm{Klf5}^{+/-}$than wild-type mice (Supplemental Figure 2C). Moreover, significantly fewer apoptotic cells were observed in both the cortex and medulla of kidneys from $\mathrm{Klf5}^{+/-}$compared with wild-type mice (Figure $1 \mathrm{H}$ and Supplemental Figure 3, A and B). In sharp contrast, interstitial fibrosis was significantly exacerbated in $\mathrm{Klf5}^{+/-}$mice, as compared with wild-type mice (Figure 

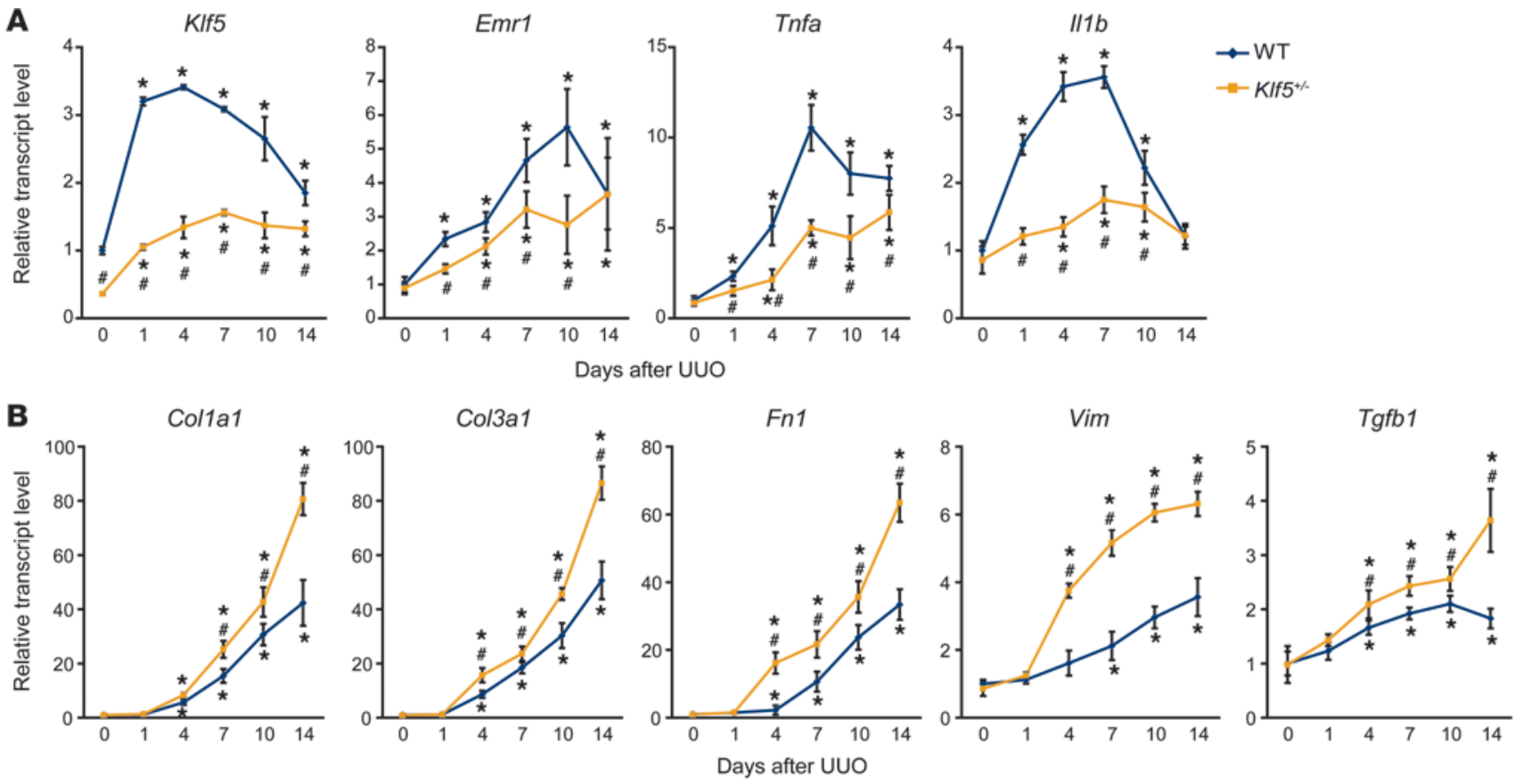

Figure 3

Effects of Klf5 haploinsufficiency on renal gene expression. Wild-type and $K I f 5^{+/-}$mice were subjected to UUO, after which relative transcript levels of genes involved in renal inflammation $(\mathbf{A})$ and fibrosis $(\mathbf{B})$ were measured the indicated times using real-time PCR. Data labeled day 0 show gene expression in kidneys under basal conditions. Expression levels were normalized first to those of $18 \mathrm{~s} r R N A$ and then further normalized to the levels in the kidneys from control wild-type mice. ${ }^{*} P<0.05$ versus the control (day 0 ) for the same genotype; ${ }^{\#} P<0.05$ versus wild-type at the same time point. $n=5$ for each point.

1, E, F, and I, Supplemental Figure 2C, and Supplemental Figure 3, C and D). It thus appears that the Klf5 haploinsufficiency protected kidneys from the structural destruction induced by UUO, but it promoted fibrosis. Because the contralateral kidneys were uninjured, neither wild-type nor $\mathrm{Klf5}^{+/-}$mice showed abnormal blood chemistry, and no mice died within 3 months after UUO (Supplemental Table 2).

To analyze the effects of Klf5 haploinsufficiency on renal dysfunction, we employed a reversible UUO procedure (22). Initially, the right ureter was obstructed for 3 days, and then the obstruction was released. After mice were allowed to recover for 7 days, the left ureter was ligated to disable contralateral kidney function. After an additional 7 days, the right kidneys of $\mathrm{Klf5}^{+/-}$mice exhibited less renal injury than those of wild-type mice (Figure 2, A and B), though fibrosis was more pronounced in the Klf5 $5^{+-}$kidney. Blood urea nitrogen (BUN) levels were significantly lower in $\mathrm{Klf5}^{+/-}$than wild-type mice, while body weights were not different (Figure 2C). These results demonstrate that Klf5 haploinsufficiency protected kidneys from dysfunction induced by the transient UUO, despite the apparent augmentation in fibrosis.

Klf5 haploinsufficiency modulates renal inflammation and fibrosis induced by UUO. Recent studies suggest that inflammation is crucially involved in renal cellular injury and fibrosis (23). This prompted us to assess the involvement of KLF5 in inflammatory processes in the kidney. We found that, in wild-type mice, UUO increased renal expression of Tnfa and $I l 1 b$, which encode the proinflammatory cytokines TNF- $\alpha$ and IL- $1 \beta$, respectively (Figure 3A); that the expression levels were highest 7 days after UUO; and that the levels of these proinflammatory cytokines were significantly reduced in $\mathrm{Klf5}^{+/-}$kidneys following UUO. In wild-type kidneys, UUO also increased expression of Emr1, which encodes the macrophage marker $\mathrm{F} 4 / 80$, and that effect was significantly reduced in $\mathrm{Klf5}^{+/-}$kidneys, suggesting that UUO-induced renal infiltration by macrophages and their inflammatory activation are diminished in $\mathrm{Klf5}^{+/-}$kidneys. As expected from the enhanced fibrosis, expression levels of Col1a1 and Col3a1, encoding collagen type I and III, respectively; Fn1, encoding fibronectin; Vim, encoding vimentin; and Acta2, encoding $\alpha$-SMA, were all significantly increased in $\mathrm{Klf5}^{+/-}$kidneys, and their expression was highest 14 days after UUO (Figure 3B). In addition, expression of Tgfb1, which encodes the profibrotic cytokine TGF- $\beta 1$, was also significantly increased in $\mathrm{Klf5}^{+/-}$kidneys. As a result, the interstitial area in $\mathrm{Klf5}^{+/-}$kidneys was reduced after UUO due to a reduction in the number of apoptotic cells, whereas the fibrotic area and the fibrotic/interstitial area ratio were increased in $\mathrm{Klf5}^{+/-}$kidneys (Supplemental Figure 3D). Collectively, these results suggest that Klf5 haploinsufficiency suppresses early inflammatory processes following UUO, while augmenting fibrotic processes at later times.

Differential recruitment of macrophage subtypes to kidneys after UUO. The reduction in F4/80 expression observed in $\mathrm{Klf5}^{+/-}$kidneys suggests that macrophage accumulation was suppressed there. We tested that idea using flow cytometry to assess renal macrophages (Supplemental Figure 4A). In wild-type mice, UUO induced accumulation of $\mathrm{CD} 11 \mathrm{~b}^{+} \mathrm{F} 4 / 80^{+}$cells (Figure $4 \mathrm{~A}$ ), and we noted two major subpopulations: $\mathrm{CD} 11 \mathrm{~b}^{+} \mathrm{F} 4 / 80^{\mathrm{lo}}(\mathrm{R} 1)$ and $\mathrm{CD} 11 \mathrm{~b}^{+} \mathrm{F} 4 / 80^{\mathrm{hi}}$ (R2). Under basal conditions the $\mathrm{CD} 11 \mathrm{~b}^{+} \mathrm{F} 4 / 80^{\mathrm{hi}}$ fraction was significantly larger than the $\mathrm{CD} 11 \mathrm{~b}^{+} \mathrm{F} 4 / 80^{\text {lo }}$ fraction (Figure $4 \mathrm{~B}$ ), but the latter was increased from day 1 after UUO, while the former 
A
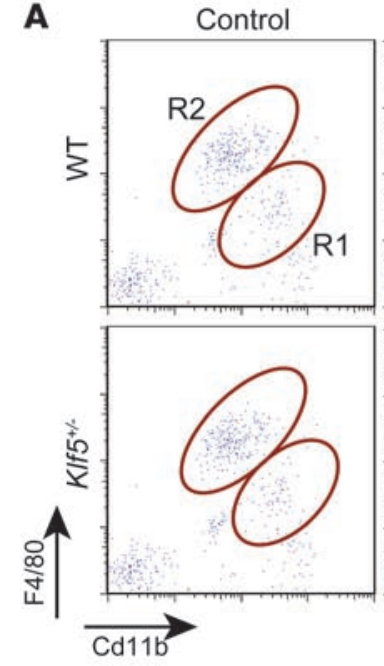

Day 1 after UUO
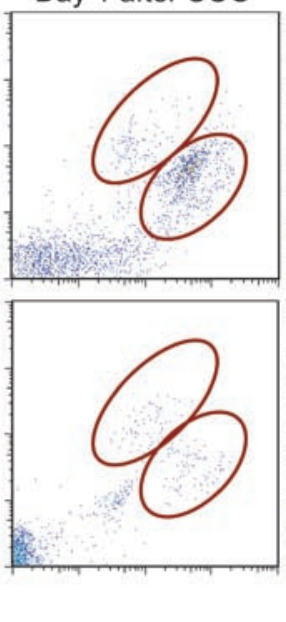

Day 7 after UUO
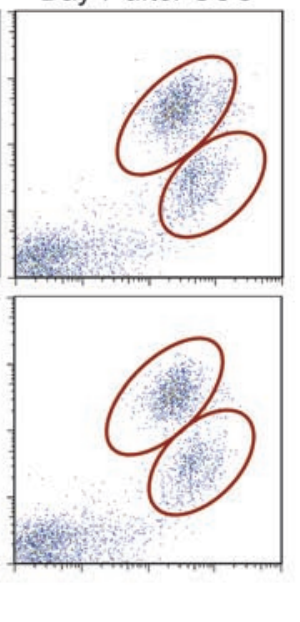

B $(\%)$

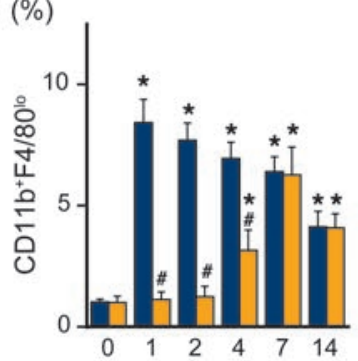

(\%)

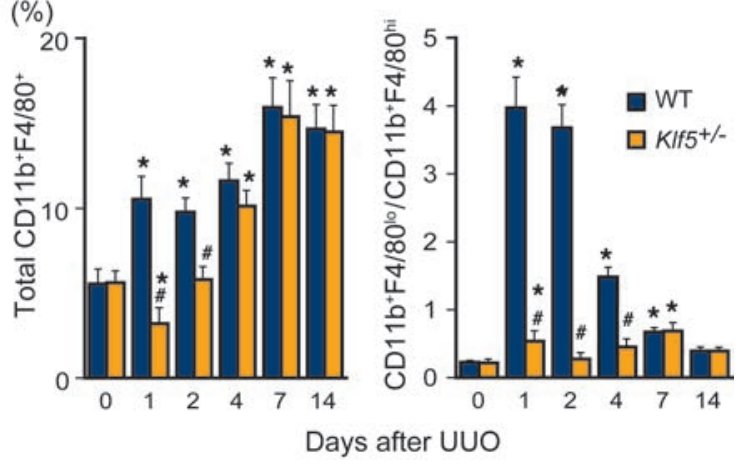

(\%)

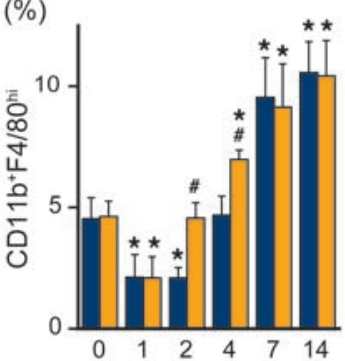

Figure 4

KLF5 controls the recruitment and accumulation of $\mathrm{CD} 11 \mathrm{~b}+\mathrm{F} 4 / 80^{+}$cells in response to UUO. (A) Representative flow cytometry plots of macrophages in whole kidneys from wild-type and $K I f 5^{+-}$mice subjected to either UUO or sham operation. $R 1$ and $R 2$ indicate $C D 11 b^{+} F 4 / 80^{l o}$ and CD11 b+F4/80 hi cells, respectively. (B) Fractions of CD11b+F4/80'o (region R1 in A), CD11b+F4/80 hi (R2), and total CD11b+F4/80+ cells among total live cells and the ratios of $C D 11 b^{+} F 4 / 80^{\text {lo }}$ to $C D 11 b^{+} F 4 / 80^{\text {hi }}$ cells isolated from the kidneys of wild-type and $K I f 5^{+/-}$mice subjected to UUO. ${ }^{*} P<0.05$ versus day 0 of the same genotype; ${ }^{*} P<0.05$ versus wild-type at the same time point. $n=6$ for each group. The cell populations expressed as fractions of total macrophages and numbers of cells per kidney are shown in Supplemental Figure 5 , A and B.

was reduced on days 1 and 2 . As a result, the ratio of $\mathrm{CD} 11 \mathrm{~b}^{+} \mathrm{F} 4 /$ $80^{\text {lo }}$ to $\mathrm{CD} 11 \mathrm{~b}^{+} \mathrm{F} 4 / 80^{\text {hi }}$ cells was significantly increased from day 1 to day 7 . The cell ratio then declined to the basal level within 14 days after UUO.

We next characterized the surface phenotypes of CD $11 \mathrm{~b}^{+} \mathrm{F} 4 / 80^{+}$ cells and found that while $\mathrm{CD} 11 \mathrm{~b}^{+} \mathrm{F} 4 / 80^{\text {lo }}$ cells were $\mathrm{Ly}-6 \mathrm{C}^{+}$, $\mathrm{CD} 11 \mathrm{~b}^{+} \mathrm{F} 4 / 80^{\mathrm{hi}}$ cells were $\mathrm{Ly}-6 \mathrm{C}^{-/ \mathrm{lo}}$, and majorities of both cell populations were negative for the granulocyte marker Ly-6G (Supplemental Figure 4B). They were also negative for the myeloidderived suppressor cell marker CD93 (24). In addition, while both $\mathrm{CD} 11 \mathrm{~b}^{+} \mathrm{F} 4 / 80^{\text {lo }}$ and $\mathrm{CD} 11 \mathrm{~b}^{+} \mathrm{F} 4 / 80^{\text {hi }}$ cells showed greater forward scatter (FSC) on day 7 than day 1 after $\mathrm{UUO}, \mathrm{CD} 11 \mathrm{~b}^{+} \mathrm{F} 4 / 80^{\text {hi }}$ cells showed much greater FSC than CD $11 b^{+} \mathrm{F} 4 / 80^{\text {hi }}$ cells on day 7 (Supplemental Figure 4C). In Cytospin preparations, CD11b ${ }^{+} \mathrm{F} 4 /$ $80^{\text {lo }}$ cells exhibited a small, monocytoid morphology on day 1 but also included larger cells by day 7 (Supplemental Figure 4D). In contrast, $\mathrm{CD} 11 \mathrm{~b}^{+} \mathrm{F} 4 / 80^{\text {hi }}$ cells were larger than $\mathrm{CD} 11 \mathrm{~b}^{+} \mathrm{F} 4 / 80^{\text {lo }}$ cells and had a fried egg-like morphology. Despite their monocytoid morphology, day- $1 \mathrm{CD} 11 \mathrm{~b}^{+} \mathrm{F} 4 / 80^{\text {lo }}$ cells showed higher surface F4/80 and CD11b levels than circulating CD $11 b^{+}$Ly-6C $C^{+}$inflammatory monocytes, which have been shown to be recruited to kidneys after UUO (11). This suggests $C D 11 b^{+} F 4 / 80^{\text {lo }}$ cells include macrophages as well as monocytes that had been recruited to the kidneys, where they are undergoing differentiation into macrophages $(11,25)$, while $\mathrm{CD} 11 \mathrm{~b}^{+} \mathrm{F} 4 / 80^{\text {hi }}$ cells are more mature macrophages. Moreover, $\mathrm{CD} 11 \mathrm{~b}^{+} \mathrm{F} 4 / 80^{\text {hi }}$ cells but not $\mathrm{CD} 11 \mathrm{~b}^{+} \mathrm{F} 4 / 80^{\text {lo }}$ cells were positive for CD206 and CD301, markers of M2-type activation. Collectively then, the two populations of $\mathrm{CD} 11 \mathrm{~b}^{+} \mathrm{F} 4 / 80^{+}$ cells in UUO kidneys exhibited a CD11b+F4/80 ${ }^{\mathrm{lo}} \mathrm{Ly}-6 \mathrm{C}^{+} \mathrm{CD} 206^{-}$
CD301- phenotype, which is indicative of M1-type activation, and a CD $11 \mathrm{~b}^{+} \mathrm{F} 4 / 80^{\mathrm{hi}} \mathrm{Ly}-6 \mathrm{C}^{-/} / \mathrm{L} \mathrm{Ly}-6 \mathrm{G}^{-} \mathrm{CD} 206^{+} \mathrm{CD} 301^{+}$phenotype, which is indicative of M2-type activation $(11,26)$.

Under basal conditions there were no significant differences in the $\mathrm{CD} 11 \mathrm{~b}^{+} \mathrm{F} 4 / 80^{\text {lo }}$ and $\mathrm{CD} 11 \mathrm{~b}^{+} \mathrm{F} 4 / 80^{\text {hi }}$ fractions between wildtype and $\mathrm{Klf5}^{+/-}$kidneys (Figure 4B and Supplemental Figure 5, $\mathrm{A}$ and $\mathrm{B}$ ). However, $\mathrm{Klf5}^{+/-}$kidneys contained significantly fewer $\mathrm{CD} 11 \mathrm{~b}^{+} \mathrm{F} 4 / 80^{\text {lo }}$ cells from day 1 to day 4 after UUO. By contrast, $\mathrm{Klf5}^{+/-}$kidneys contained more $\mathrm{CD} 11 \mathrm{~b}^{+} \mathrm{F} 4 / 80^{\text {hi }}$ cells on days 2 and 4 than wild-type kidneys (Figure 4B and Supplemental Figure 5, A and $\mathrm{B})$. As a result, the $\mathrm{CD} 11 \mathrm{~b}^{+} \mathrm{F} 4 / 80^{\text {lo }}$ to $\mathrm{CD} 11 \mathrm{~b}^{+} \mathrm{F} 4 / 80^{\text {hi }}$ ratio was significantly higher than baseline only on days 1 and 7 in $\mathrm{Klf5}^{+/-}$kidneys. Reduced inflammatory monocyte/macrophage infiltration into $\mathrm{Klf5}^{+/-}$kidneys 1 day after UUO was further confirmed by immunohistochemical staining for F4/80 and Ly-6C (Supplemental Figure 5, C and D). Taken together, these findings suggest that $\mathrm{CD} 11 \mathrm{~b}^{+} \mathrm{F} 4 / 80^{\mathrm{lo}}$ and $\mathrm{CD} 111 \mathrm{~b}^{+} \mathrm{F} 4 / 80^{\mathrm{hi}}$ cells differentially accumulate in the kidney during the course of the response to UUO. At early times, when apoptosis and tissue destruction are occurring, primarily $\mathrm{CD} 11 \mathrm{~b}^{+} \mathrm{F} 4 / 80^{\mathrm{lo}}$ monocytes/macrophages accumulate in kidneys. Later, when tissue remodeling and fibrosis dominate, the numbers of $\mathrm{CD} 11 \mathrm{~b}^{+} \mathrm{F} 4 / 80^{\mathrm{hi}}$ macrophages are increased. Klf5 haploinsufficiency reduces accumulation of $\mathrm{CD} 11 \mathrm{~b}^{+} \mathrm{F} 4 / 80^{\text {lo }}$ cells and increases $\mathrm{CD} 11 \mathrm{~b}^{+} \mathrm{F} 4 / 80^{\text {hi }}$ cells at earlier time points, thereby altering the balance of macrophage polarity during the response to UUO.

Renal $\mathrm{CD} 11 \mathrm{~b}^{+} \mathrm{F} 4 / 80^{+}$cells are phenotypically different from splenic classical DCs. DCs have been identified in kidneys (27-29). Although CD11c has been used to distinguish renal DCs from macrophages (30), the marker is widely expressed and is induc- 


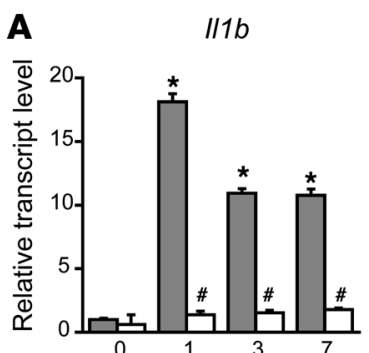

$\mathrm{Ccl} 2$

Ly6c

$1 / 10$

Tgfb1
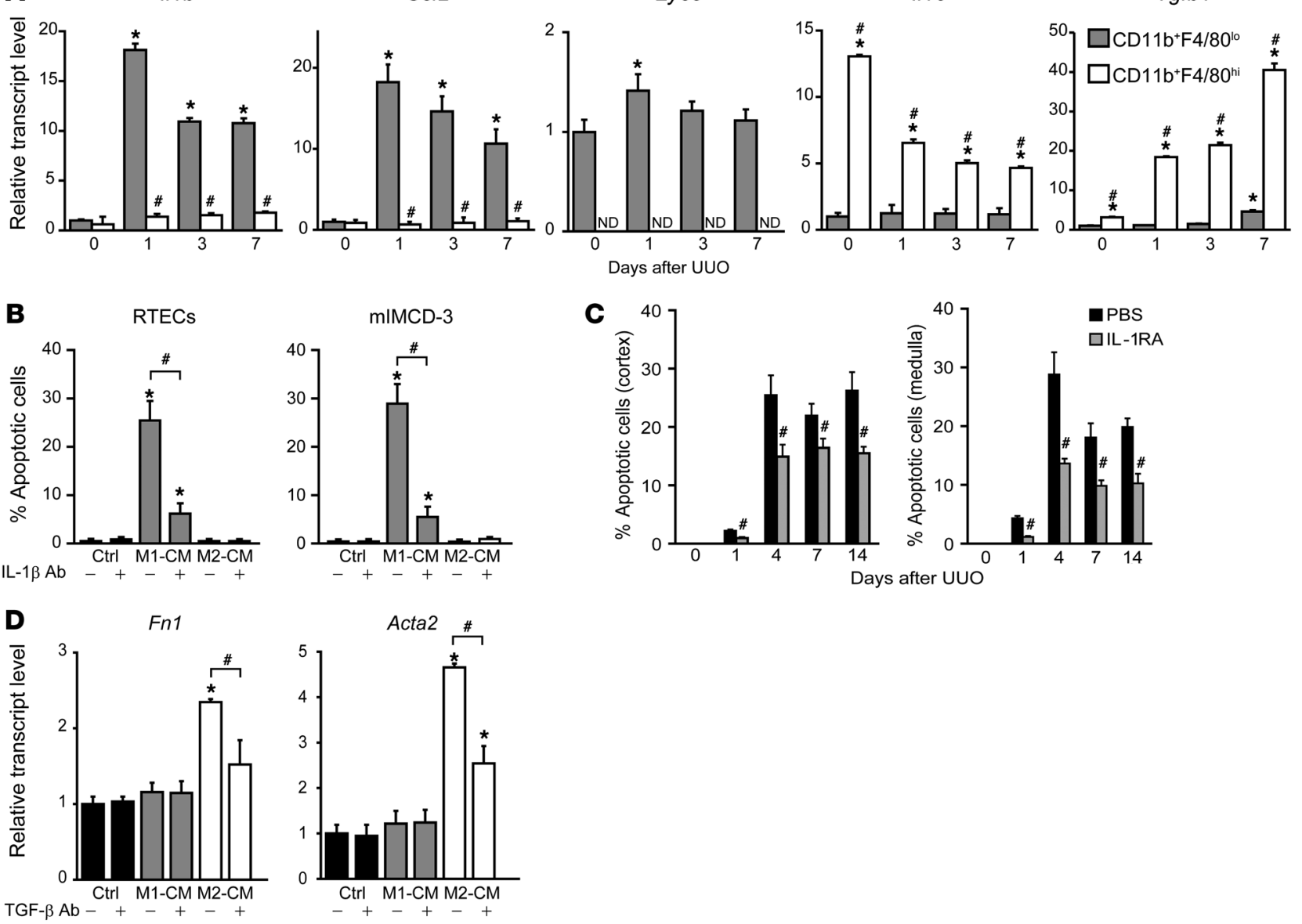

Figure 5

Differential involvement of $C D 11 b+F 4 / 80^{10}$ and $C D 11 b+F 4 / 80^{\text {hi }}$ cells in renal responses to $U U O$. (A) mRNA expression in $C D 11 b+F 4 / 80^{\text {lo }}$ and $\mathrm{CD} 11 \mathrm{~b}+\mathrm{F} 4 / 80^{\text {hi }}$ cells isolated from kidneys under basal conditions (day 0 ) or after UUO. Expression levels were normalized to those of $18 \mathrm{~s} r R N A$ and then further normalized to the levels in the resident $\mathrm{CD} 11 \mathrm{~b}+\mathrm{F} 4 / 80^{\mathrm{lo}}$ cells isolated from normal kidneys of wild-type mice. $n=3$. ${ }^{\#} P<0.05$ versus $\mathrm{CD} 11 \mathrm{~b}+\mathrm{F} 4 / 80^{\text {lo }}$ cells from wild-type mice at the same time point. ${ }^{*} P<0.05$ versus day 0 of the same population. ND, nondetectable. (B)

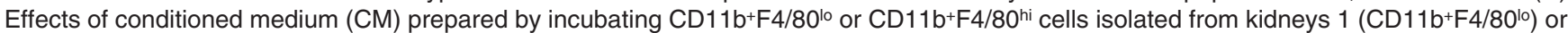
$7\left(\mathrm{CD} 11 \mathrm{~b}+\mathrm{F} 4 / 80^{\mathrm{hi}}\right)$ days after UUO in serum-free RPMI medium for 24 hours. Serum-free RPMI containing $0.3 \%$ BSA was used as a control medium (Ctrl). Fractions of TUNEL+ apoptotic primary mouse RTECs and mIMCD-3 cells after culture in the CM with either control IgG or IL-1 $\beta$ neutralizing antibody for 24 hours. $n=6$. Expression levels were normalized to those of $18 \mathrm{~s} r R N A$ and then further normalized to the levels in cells treated with the control medium. ${ }^{*} P<0.05$. versus cells in control medium with control IgG; $\# P<0.05$. (C) Effects of IL-1RA administration on UUO responses. Renal phenotypes of wild-type mice intraperitoneally administered either PBS (vehicle) or IL-1RA ( $200 \mu \mathrm{g}$ daily). ${ }^{*} P<0.05$ versus the PBS group at the same time point. $n=6$. (D) Levels of $F n 1$ and Acta2 transcription in 10T1/2 embryo fibroblasts cultured for 24 hours in $\mathrm{CM}$ as in $\mathbf{B}$ with either control IgG or TGF- $\beta$ neutralizing antibody. ${ }^{*} P<0.05$ versus cells in control medium with control IgG; ${ }^{\#} P<0.05$. $n=3$.

ible in macrophages and other immune cells during inflammation (31). To better characterize renal $\mathrm{CD}_{11} \mathrm{~b}^{+}$cells in comparison with bona fide DCs, we assessed the expression of multiple DC markers in renal CD $11 \mathrm{~b}^{+}$cells and splenic classical DCs (Supplemental Figure 6). We found that $\mathrm{CD} 11 \mathrm{~b}^{+} \mathrm{F} 4 / 80^{\text {lo }}$ cells were $\mathrm{CD} 11 \mathrm{c}^{\mathrm{lo}} \mathrm{MHCII}^{-/+} \mathrm{CD} 86^{-} \mathrm{CD} 83^{-}$, which supports the notion that they are monocytes/macrophages. $\mathrm{CD} 11 \mathrm{~b}^{+} \mathrm{F} 4 / 80^{\text {hi }}$ cells were $\mathrm{CD} 11 \mathrm{c}^{\text {int }} \mathrm{MHCII}^{+} \mathrm{CD} 86^{+} \mathrm{CD}^{2} 3^{-}$. As compared with splenic classical DCs, CD11c levels were lower in renal CD $11 b^{+} F 4 / 80^{\text {hi }}$ cells, and CD83, a marker for mature DCs $(32,33)$, was not expressed. In Cytospin preparations, $\mathrm{CD} 11 \mathrm{~b}^{+} \mathrm{F} 4 / 80^{\text {hi }}$ cells contained vacuolar cytoplasm and lacked cytoplasmic extensions, which are macrophage-like characteristics and different from those of splenic DCs (Supplemental Figure 4D and Supplemental Figure
$7 \mathrm{~A})$. These results indicate that renal $\mathrm{CD} 11 \mathrm{~b}+\mathrm{F} 4 / 80^{\text {hi }}$ cells express several DC markers, but their phenotypes differ from those of splenic classical DCs.

Because we were not able to identify a cell population that resembled splenic DCs among the CD11 $\mathrm{b}^{+}$cells, we tested whether cells expressing high levels of CD11c might be present among the renal leukocytes $\left(\mathrm{CD} 45^{+}\right.$cells). We found that CD $11 \mathrm{c}^{\text {hi }}$ cells were present and were $\mathrm{CD} 11 \mathrm{c}^{\text {hi }} \mathrm{MHCII}{ }^{+} \mathrm{CD} 86^{+} \mathrm{CD} 83^{+} \mathrm{CD} 11 \mathrm{~b}-\mathrm{F} 4 / 80^{\text {lo }}$, which is a phenotype that closely resembles that of splenic DCs (Supplemental Figure 6D). In Cytospin preparations, moreover, renal CD11 $\mathrm{c}^{\mathrm{hi}}$ cells had pleomorphic nuclei and cytoplasmic extensions, and were morphologically similar to splenic DCs (Supplemental Figure 7B). The renal $\mathrm{CD} 11 \mathrm{c}^{\text {hi }} \mathrm{MHCII}{ }^{+} \mathrm{CD} 83^{+}$cells were widely distributed on FSC/side scatter (SSC) plots, and the majority was found 
A

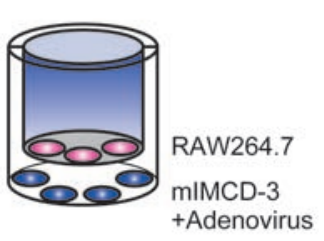

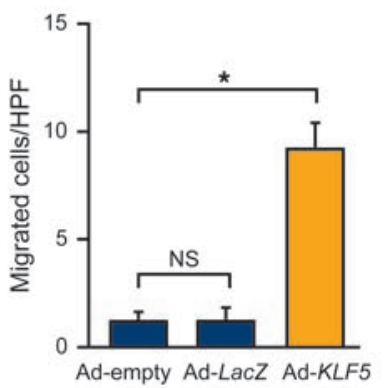

D

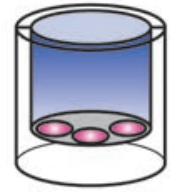

RAW264.7
S100A8/A9

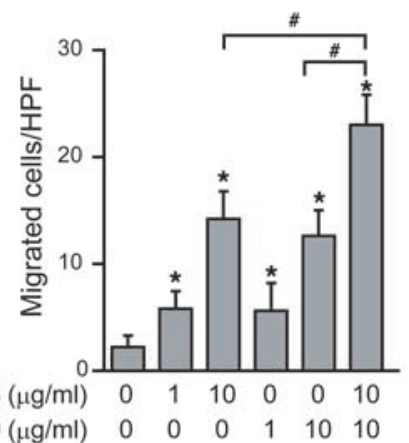

B

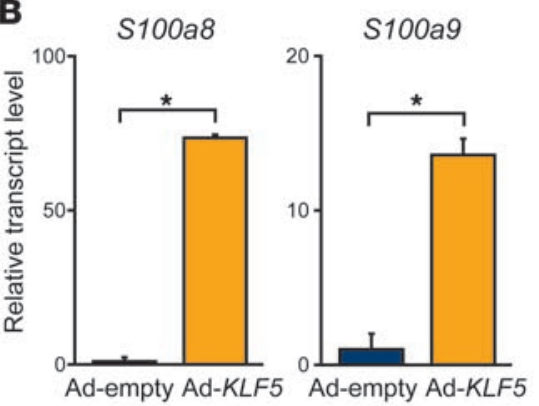

C

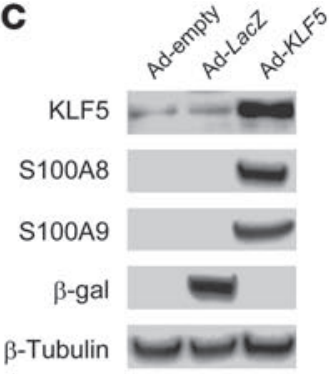

E

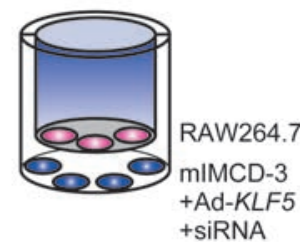

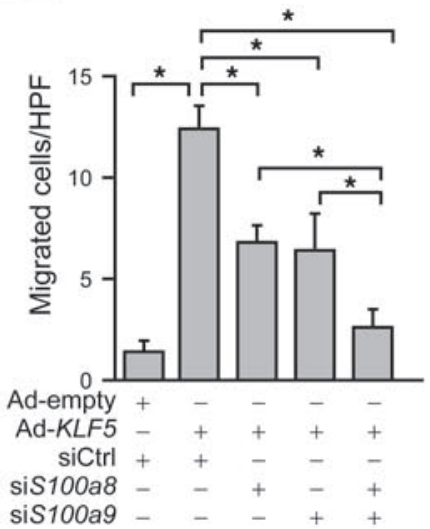

Figure 6

KLF5 induces accumulation of M1 macrophages via S100A8 and S100A9. (A) Activation of RAW264.7 macrophage migration by mIMCD-3 cells overexpressing KLF5. As shown schematically, mIMCD-3 and RAW264.7 cells were plated in the bottom wells and inserts, respectively. The mIMCD-3 cells were infected with empty adenovirus (Ad-empty), adenovirus expressing $\beta$-galactosidase (Ad-LacZ), or adenovirus expressing KLF5 (Ad-KLF5), as indicated. The numbers of cells that migrated through the porous membranes per high-power field (HPF) during the 8-hour incubation are shown. $n=12 .{ }^{*} P<0.05$. (B and C) Levels of S100a8 and S100a9 transcription in mIMCD-3 cells overexpressing KLF5. Relative levels of $\mathrm{S100a8}$ and S100a9 transcripts were determined by real-time PCR (B). $n=6$. ${ }^{\star} P<0.05$. In C, expression of KLF5, S100A8, S100A9 protein and $\beta$-galactosidase were assessed by Western blotting. $\beta$-Tubulin was used as a loading control. (D) Effects of recombinant S100A8 and S100A9 on RAW264.7 cell migration. Recombinant S100A8 and/or S100A9 were added to the medium in the lower wells, as shown. $n=6$. ${ }^{*} P<0.05$ versus migrated cells without $S 100$ proteins; $\#<0.05$. (E) Effects of $S 100 a 8$ and/or $S 100 a 9$ knockdown in mIMCD-3 cells overexpressing KLF5 on RAW264.7 migration. mIMCD-3 cells overexpressing KLF5 were transfected with siRNAs against S100a8 and S100a9 or control siRNA (siCtrl), as indicated, after which they were plated in the bottom wells, as shown. The numbers of RAW264.7 cells that migrated during the 8-hour incubation are shown. $n=6$. ${ }^{*} P<0.05$.

outside of the R3 gate that was used to characterize CD11 $\mathrm{b}^{+}$cells (Supplemental Figures 4A and 7C), indicating that these cells were not included in our $\mathrm{CD} 11 \mathrm{~b}^{+} \mathrm{F} 4 / 80^{\mathrm{hi}}$ and $\mathrm{CD} 11 \mathrm{~b}^{+} \mathrm{F} 4 / 80^{\text {lo }}$ cell populations. In addition, the renal $\mathrm{CD} 11 \mathrm{c}^{\text {hi }} \mathrm{MHCII}^{+} \mathrm{CD} 83^{+}$cell fractions were not affected by UUO or Klf5 haploinsufficiency, making it unlikely that these cells contribute to the renal phenotypes observed in $\mathrm{Klf5}^{+/-}$mice (Supplemental Figure 7D). Collectively then, it appears that kidneys contain a CD $11 \mathrm{c}^{\text {hi}} \mathrm{MHCII}{ }^{+} \mathrm{CD} 83^{+}$cell population that closely resembles classical DCs. By contrast, the surface marker profile and cellular morphology of $\mathrm{CD} 11 \mathrm{~b}^{+} \mathrm{F} 4 / 80^{\mathrm{hi}}$ cells are different from those of classical DCs. Because they differ from both splenic classical DCs and renal classical DC-like cells, and more resemble tissue macrophages in other tissues (34), we will refer to $\mathrm{CD} 11 \mathrm{~b}^{+} \mathrm{F} 4 / 80^{\text {hi }}$ cells as macrophages hereafter.

$\mathrm{CD} 11 b^{+} \mathrm{F} 4 / 80^{\text {lo }}$ and $\mathrm{CD} 11 b^{+} \mathrm{F} 4 / 80^{\text {bi }}$ cells differentially affect epithelial and mesenchymal cells. To analyze the functions of renal $\mathrm{CD} 11 \mathrm{~b}^{+} \mathrm{F} 4 / 80^{+}$cells in more detail, we isolated them from kidneys at various times after UUO (Supplemental Figure 8A). Analysis of mRNA expression in $\mathrm{CD} 11 \mathrm{~b}^{+} \mathrm{F} 4 / 80^{\mathrm{lo}}$ and $\mathrm{CD} 11 \mathrm{~b}^{+} \mathrm{F} 4 /$ $80^{\text {hi }}$ cells isolated $0,1,3$, and 7 days after UUO showed that levels of $I l 1 b$ and $C c l 2$ transcripts, encoding the proinflammatory cytokines IL-1 $\beta$ and MCP- 1 , respectively, were much higher in $\mathrm{CD} 11 \mathrm{~b}^{+} \mathrm{F} 4 / 80^{\text {lo }}$ than $\mathrm{CD} 11 \mathrm{~b}^{+} \mathrm{F} 4 / 80^{\text {hi }}$ cells (Figure $5 \mathrm{~A}$ ), suggesting that $\mathrm{CD} 11 \mathrm{~b}^{+} \mathrm{F} 4 / 80^{\text {lo }}$ cells promote inflammation. Ly6c was expressed in $\mathrm{CD} 11 \mathrm{~b}^{+} \mathrm{F} 4 / 80^{\text {lo }}$ cells, but was undetectable in $\mathrm{CD} 11 \mathrm{~b}^{+} \mathrm{F} 4 / 80^{\text {hi }}$ cells. By contrast, $\mathrm{CD} 11 \mathrm{~b}^{+} \mathrm{F} 4 / 80^{\mathrm{hi}}$ cells showed higher levels of Il10 and Tgfb1 transcripts, encoding the antiinflammatory cytokines IL-10 and TGF- $\beta 1$, respectively, which suggests the $\mathrm{CD} 11 \mathrm{~b}^{+} \mathrm{F} 4 / 80^{\text {hi }} \mathrm{M} 2$-type macrophages are involved in fibrosis and resolution of inflammation. However, $\mathrm{CD} 11 \mathrm{~b}^{+} \mathrm{F} 4 / 80^{\text {hi }}$ cells did not express two other M2 markers, $Y m 1$ and Fizz1 (data not shown), indicating that the characteristics of $\mathrm{CD} 11 \mathrm{~b}^{+} \mathrm{F} 4 / 80^{\text {hi }}$ cells do not perfectly match those of the M2 macrophages previously studied in vitro (9).

To further investigate the functional differences between $\mathrm{CD} 11 \mathrm{~b}^{+} \mathrm{F} 4 / 80^{\text {lo }}$ and $\mathrm{CD} 11 \mathrm{~b}^{+} \mathrm{F} 4 / 80^{\text {hi }}$ cells, we incubated cultured primary mouse renal tubular epithelial cells (RTECs) and mIMCD3 mouse collecting duct epithelial cells in medium conditioned by either $\mathrm{CD} 11 \mathrm{~b}^{+} \mathrm{F} 4 / 80^{\text {lo }}$ or $\mathrm{CD} 11 \mathrm{~b}^{+} \mathrm{F} 4 / 80^{\mathrm{hi}}$ cells isolated from kidneys subjected to UUO. The surface phenotypes and cytokine gene expression profiles of $\mathrm{CD} 11 \mathrm{~b}^{+} \mathrm{F} 4 / 80^{\mathrm{lo}}$ and $\mathrm{CD} 11 \mathrm{~b}^{+} \mathrm{F} 4 / 80^{\mathrm{hi}}$ cells cultured for 24 hours were similar to those of the cells just after 
A

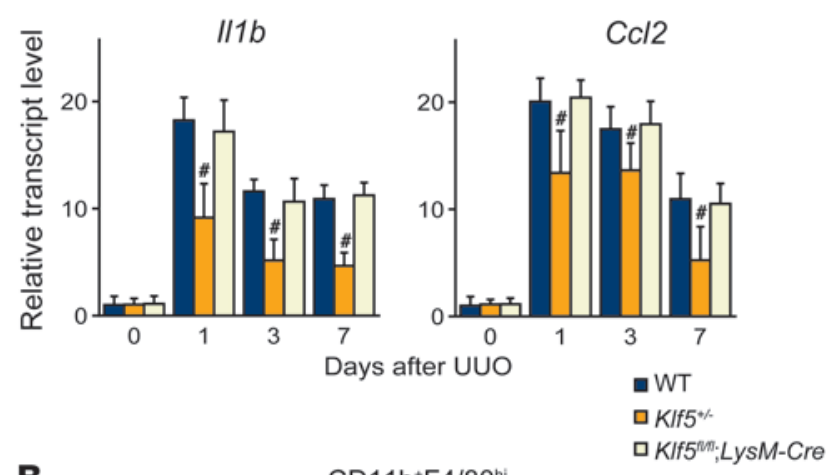

B

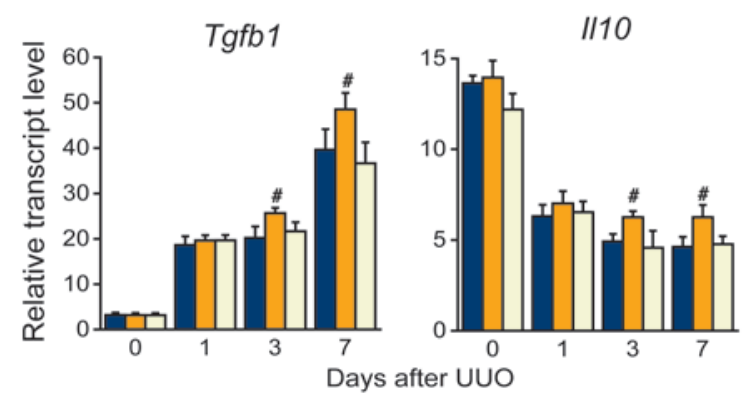

Figure 7

Effects of global and macrophage-specific KIf5 deletion on macrophage cytokine gene expression. Expression of cytokine genes in $\mathrm{CD} 11 \mathrm{~b}+\mathrm{F} 4 /$ $80^{10}(A)$ and $C D 11 b^{+} \mathrm{F} 4 / 80^{\text {hi }}(B)$ cells isolated from kidneys of wild-type, $\mathrm{KIF}^{+/-}$, and $\mathrm{KIf5} \mathrm{fllfl}^{\prime} \mathrm{LySM}$-Cre mice at indicated days after UUO. Expression levels were normalized to those of 18s rRNA and then further normalized to the levels in cells in wild-type kidney under basal conditions. $n=3$. ${ }^{\#} P<0.05$ versus cells of wild-type mice at the same time point.

isolation (Supplemental Figure 8, B and C). We observed much higher frequencies of apoptosis among RTECs and mIMCD-3 cells in medium conditioned by $\mathrm{CD} 11 \mathrm{~b}^{+} \mathrm{F} 4 / 80^{\text {lo }}$ cells than among those in medium conditioned by $\mathrm{CD} 11 \mathrm{~b}^{+} \mathrm{F} 4 / 80^{\mathrm{hi}}$ macrophages (Figure $5 \mathrm{~B})$. In fact, the $\mathrm{CD} 11 \mathrm{~b}^{+} \mathrm{F} 4 / 80^{\text {hi }}$-conditioned medium induced apoptosis in very few cells. Moreover, the proapoptotic effect of $\mathrm{CD} 11 \mathrm{~b}^{+} \mathrm{F} 4 / 80^{\text {lo }}$-conditioned medium was significantly suppressed by an anti-IL-1 $\beta$ neutralizing antibody. In line with these in vitro observations, inhibition of IL-1 receptor signaling by IL-1 receptor antagonist (IL-1RA) suppressed renal injury and renal cell apoptosis in UUO (Figure 5C and Supplemental Figure 9). The $\mathrm{CD} 11 \mathrm{~b}^{+} \mathrm{F} 4 / 80^{\mathrm{hi}}$-conditioned medium induced expression of Fn1 and Acta2, encoding fibronectin 1 and $\alpha$-SMA, in C3H10T1/2 mouse embryonic fibroblasts, which is indicative of the cells' activation into myofibroblasts, and this myofibroblastic differentiation was significantly suppressed by an anti-TGF- $\beta$ neutralizing antibody (Figure 5D). These results demonstrate that $\mathrm{CD} 11 \mathrm{~b}^{+} \mathrm{F} 4 /$ $80^{\text {lo }}$ monocytes/macrophages induce renal epithelial cell injury via inflammatory cytokines, including IL- $1 \beta$, whereas CD $11 \mathrm{~b}^{+} \mathrm{F} 4 / 80^{\mathrm{hi}}$ M2-type macrophages appear to promote fibrosis by inducing myofibroblastic differentiation, at least in part, via TGF- $\beta$.

KLF5 controls expression of S100A8 and S100A9, which induce migration and $M 1$ activation in macrophages. The results summarized so far suggest that renal KLF5 is involved in the accumulation of $\mathrm{CD} 11 \mathrm{~b}^{+} \mathrm{F} 4 / 80^{\text {lo }}$ monocytes/macrophages in the kidney. To test this possibility direct- ly, we cultured mIMCD-3 cells infected with KLF5-expressing (AdKLF5), $\beta$-galactosidase-expressing (Ad-LacZ), or empty (Ad-empty) adenoviral vector in the bottom wells of Boyden chambers, and cultured RAW264.7 macrophages in the upper inserts (Figure 6A). The mIMCD-3 cells overexpressing KLF5 induced migration of significantly larger numbers of RAW264.7 cells than the cells infected with Ad-LacZ or empty adenovirus. This suggests that KLF5 controls production of chemoattractants. Similarly, overexpression of KLF5 in mIMCD-3 cells promoted migration of BM-derived macrophages (BMDMs) (Supplemental Figure 10A). The BMDMs had been treated with either IFN- $\gamma /$ LPS or IL-4 to induce M1 or M2 activation, respectively (35), and KLF5 overexpression in mIMCD-3 cells induced migration of more M1-activated BMDMs than M2-activated BMDMs.

We then sought the downstream KLF5 effector molecules mediating the observed macrophage migration. We identified potential KLF5 target genes by combining microarray analysis with ChIP followed by high-speed sequencing (ChIP-seq) of KLF5 binding sites. We first identified genes whose expression was upregulated by Ad-KLF5 in mIMCD-3 cells (Supplemental Table 3) and then narrowed the range of candidate genes on the basis of whether the ChIP-seq reads were in the proximity of each gene locus. Two of the candidate KLF5 target genes were S100a8 and S100a9. These genes encode the secretory proteins S100A8 and S100A9, which have been shown to induce leukocyte migration $(36,37)$. Quantitative real-time PCR and Western blot analyses confirmed upregulation of S100a8 and S100a9 expression in mIMCD-3 cells infected with Ad-KLF5 (Figure 6, B and C).

When we then tested whether S100A8 or S100A9 was capable of recruiting macrophages to kidneys, we found that recombinant S100A8 or S100A9 increased migration of RAW264.7 cells and BMDMs in Boyden chambers (Figure 6D and Supplemental Figure 10B) and that knocking down S100a8 and/or S100a9 significantly reduced RAW264.7 and BMDM migration induced by overexpression of KLF5 in mIMCD-3 cells (Figure 6E and Supplemental Figure 10, C and D). Both S100A8 and S100A9 more efficiently induced migration of M1-activated BMDMs than M2-activated BMDMs (Supplemental Figure 10B). Thus, S100A8 and S100A9 appear to be important chemoattractants controlled by KLF5.

In addition to the suppressed accumulation of $\mathrm{CD} 11 \mathrm{~b}^{+} \mathrm{F} 4 / 80^{\text {lo }}$ cells in $\mathrm{Klf5}^{+/-}$kidneys after UUO (Figure 4B), the CD $11 \mathrm{~b}^{+} \mathrm{F} 4 / 80^{\text {lo }}$ cells present expressed lower levels of $I l 1 b$ and $C c l 2$ than wild-type cells (Figure 7A). By contrast, expression of $I l 10$ and Tgfb1 in CD11b ${ }^{+} \mathrm{F} 4 /$ $80^{\text {hi }} \mathrm{M} 2$-type macrophages was increased in $\mathrm{Klf5}^{+/-}$kidneys (Figure $7 \mathrm{~B})$. Lin et al. recently demonstrated that circulating CD11 b $\mathrm{Ly}^{+} 6 \mathrm{C}^{+}$ monocytes differentiate into both M1- and M2-type macrophages in UUO kidneys (11), suggesting that the renal microenvironment plays an important role in the differential activation of macrophages. Taking this in consideration, our results suggest that Klf5 haploinsufficiency may render the renal microenvironment relatively suppressive for M1-type activation but more permissive for M2-type activation. We therefore hypothesized that S100A8 and S100A9 might also mediate M1-type activation in UUO kidneys. To test this idea, we treated BMDMs with S100A8 and S100A9 (Figure 8A). We found they induced expression of the M1 markers $I l 1 b$ and Tnfa, while the M2 markers Arg1 and Mrc1 (CD206) were unaffected, indicating that S100A8/A9 can induce M1-type activation of BMDMs.

S100A8 and S100A9 mediate accumulation and activation of macrophages in kidneys in vivo. To determine whether S100A8 and S100A9 also induce macrophage accumulation in kidneys in vivo, we directly injected recombinant S100A8 and S100A9 into the kidneys of mice, where they clearly induced accumulation of $\mathrm{CD} 11 \mathrm{~b}+\mathrm{F} 4 / 80^{\text {lo }}$ 

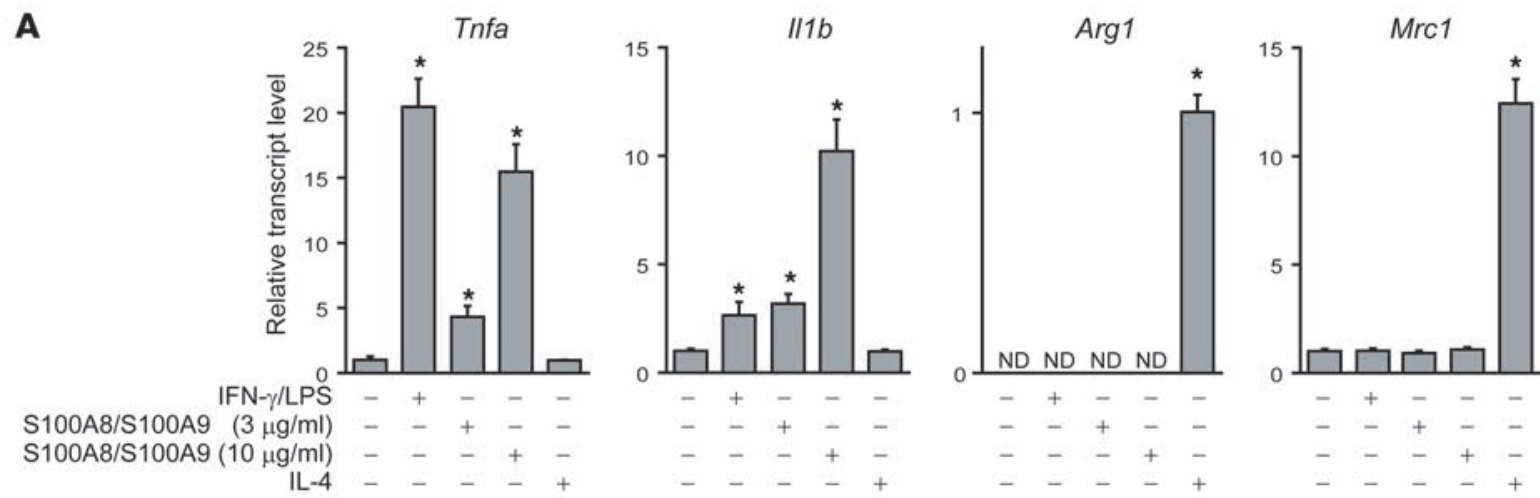

B

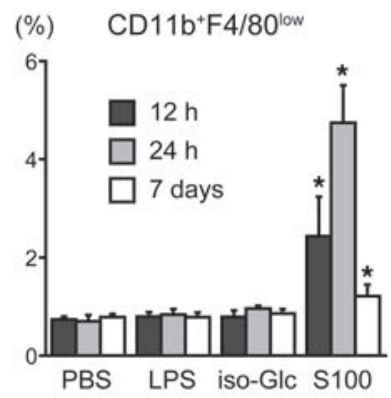

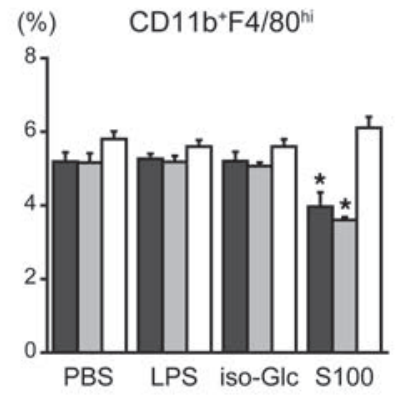

C

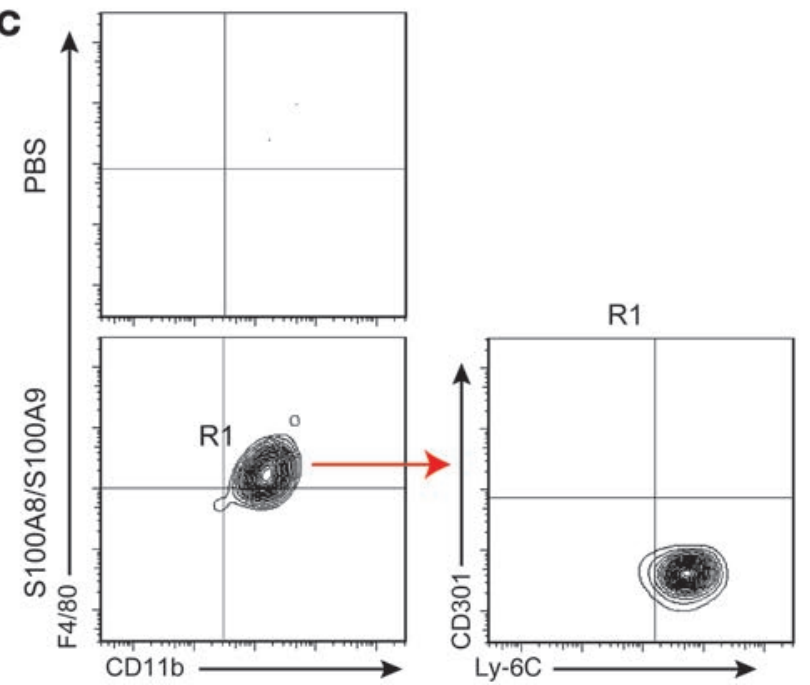

Figure 8

S100A8 and S100A9 induce M1-type activation and accumulation of CD11b+F4/80 lo cells. (A) Effects of S100A8/A9 on M1 or M2 activation of BMDMs. Unstimulated BMDMs were treated with IFN- $\gamma$ plus LPS, S100A8 plus S100A9 (3 and $10 \mu \mathrm{g} / \mathrm{ml}$ of each), or IL-4 for $24 \mathrm{hours,} \mathrm{and}$ expression of M1 and M2 markers was analyzed. Expression levels were normalized to those of 18s rRNA and then further normalized to the levels in BMDMs without stimulation, except Arg1. ${ }^{*} P<0.05$ versus untreated control. $n=3$. (B) Effect of renal injection of recombinant S100A8 and S100A9 on macrophage accumulation. A solution of recombinant S100A8 and S100A9 (S100; $25 \mu \mathrm{g}$ of each protein) was injected directly into the right kidney. The same amount of vehicle PBS, PBS containing LPS at a concentration (9.2 pg/ml) matched to that in the S100A8/A9 solution (LPS), or PBS whose osmolarity was matched to that of the $\mathrm{S} 100$ solution using glucose (iso-Glc) was injected into kidneys as control. $\mathrm{CD} 11 \mathrm{~b}+\mathrm{F} 4 / 80^{\text {lo }}$ and $\mathrm{CD} 11 \mathrm{~b}+\mathrm{F} 4 / 80^{\text {hi }}$ fractions among total live cells were determined by flow cytometry. $n=3 .{ }^{*} P<0.05$ versus kidneys 12 hours after PBS injection. (C) CD11b+Ly-6C+EGFP+ BM cells $\left(1 \times 10^{6}\right.$ cells/mouse) were prepared from CAG-EGFP mice and adoptively transferred into wild-type mice prior to a single injection of PBS or S100A8 plus S100A9 (25 $\mu \mathrm{g}$ of each) into kidneys. Transferred EGFP+ cells recruited to kidneys were analyzed by flow cytometry. Cells in R1 (CD11b+F4/80') were further analyzed for expression of Ly-6C and CD301.

cells within 12 hours (Figure 8B) and also induced moderate levels of apoptosis and tubular injury (Supplemental Figure 11). The controls, which included PBS, PBS containing LPS at a level matching that in the recombinant S100A8/A9 solution, or PBS whose osmolarity was matched to that of the S100A8/A9 solution using glucose, did not induce $\mathrm{CD} 11 \mathrm{~b}^{+} \mathrm{F} 4 / 80^{\text {lo }}$ cell accumulation (Figure 8B). The $\mathrm{CD} 11 \mathrm{~b}^{+} \mathrm{F} 4 / 80^{\mathrm{hi}} \mathrm{M} 2$-type macrophage fraction was reduced by S100A8/A9 injection, suggesting that S100A8 and S100A9 selectively recruit $\mathrm{CD} 11 \mathrm{~b}^{+} \mathrm{F} 4 / 80^{\mathrm{lo}}$ cells to the kidneys and/ or promote M1-type activation in recruited monocytes.

Previous studies have shown that CD $11 \mathrm{~b}^{+} \mathrm{Ly}-6 \mathrm{C}^{+}$inflammatory monocytes are the major monocyte population recruited to kidneys 5 days after UUO (11). Therefore, prior to UUO we adoptively transferred $\mathrm{BM} C \mathrm{CD} 11 \mathrm{~b}^{+} \mathrm{Ly}-6 \mathrm{C}^{+}$monocytes prepared from CAG-EGPF mice, in which EGFP was ubiquitously expressed (Supplemental
Figure 12). One day after UUO, the transferred EGFP ${ }^{+}$monocytes were recruited to the kidneys, and the majority of them exhibited the $\mathrm{CD} 11 \mathrm{~b}^{+} \mathrm{F} 4 / 80^{\mathrm{lo}} \mathrm{Ly}-6 \mathrm{C}^{+} \mathrm{CD} 301^{-}$phenotype, while a minor population exhibited the $\mathrm{CD} 11 \mathrm{~b}^{+} \mathrm{F} 4 / 80^{\mathrm{hi}} \mathrm{Ly}-6 \mathrm{C}^{-/ \mathrm{lo}} \mathrm{CD} 301^{+} \mathrm{M} 2$-type phenotypes (Supplemental Figure 12A). In contrast, very few CD11 b+Ly-6C- BM monocytes were recruited to UUO kidneys (data not shown). Thus, as with monocytes transferred 5 days after $\mathrm{UUO}(11), \mathrm{CD} 11 \mathrm{~b}^{+} \mathrm{Ly}-6 \mathrm{C}^{+}$ inflammatory monocytes appear to be the major source of monocytes recruited to kidneys early after UUO. The finding that expression of Emr1 (F4/80) and Il1b was increased while expression of Csf1r (CD115), which is highly expressed in monocytes (26), was decreased indicates that the recruited $\mathrm{CD} 11 \mathrm{~b}^{+} \mathrm{F} 4 / 80^{\mathrm{lo}}$ cells were differentiating into M1-type macrophages. This supports the notion that kidney $\mathrm{CD} 11 \mathrm{~b}^{+} \mathrm{F} 4 / 80^{\text {lo }}$ cells include macrophages and newly recruited monocytes differentiating into macrophages. 
A

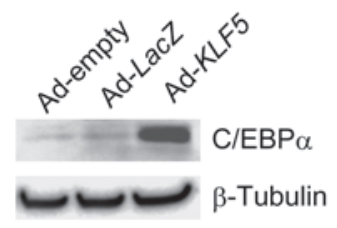

B
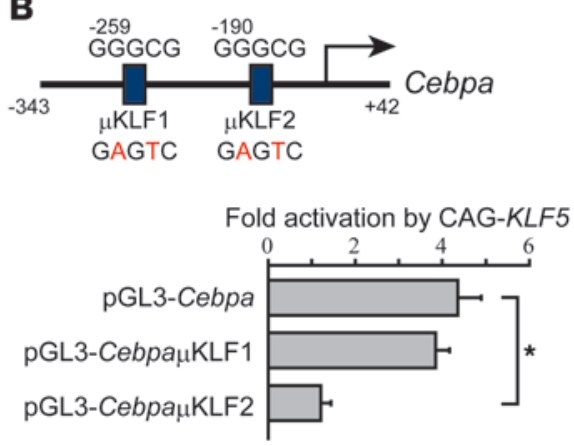

C pGL3-S100a8

pGL3-S100a9
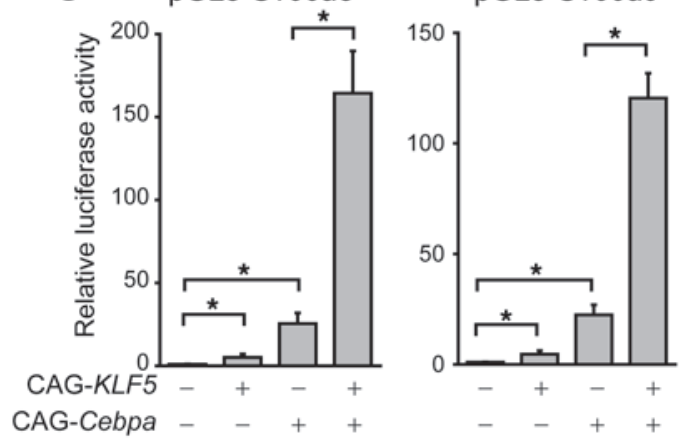

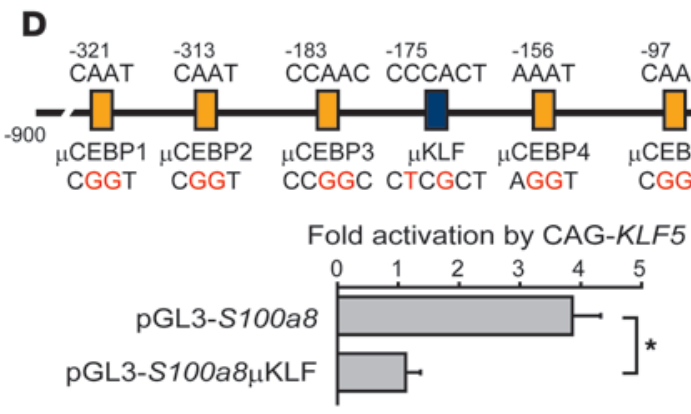

Fold activation by CAG-Cebpa

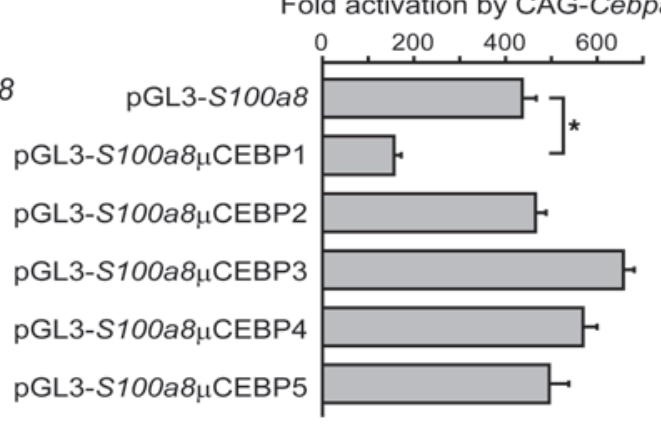

E

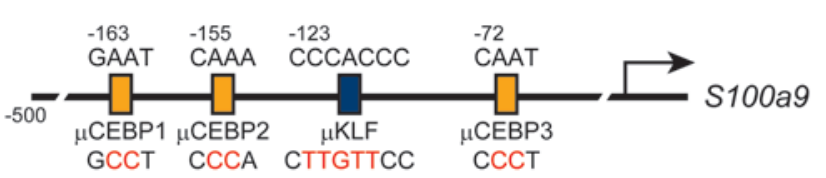

Fold activation by CAG-KLF5

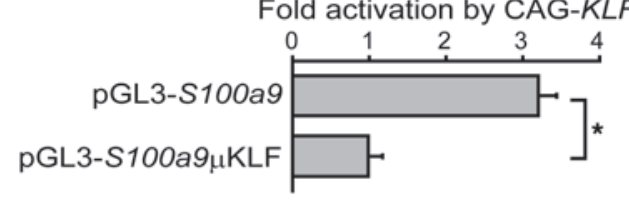

S100a8

pGL3-S100a8 $\mu$ CEBP

pGL3-S100a8 $\mu$ CEBP2

pGL3-S100a8 $\mu$ CEBP3

pGL3-S100a8 $\mu$ CEBP4

pGL3-S100a8nCEBP5

.
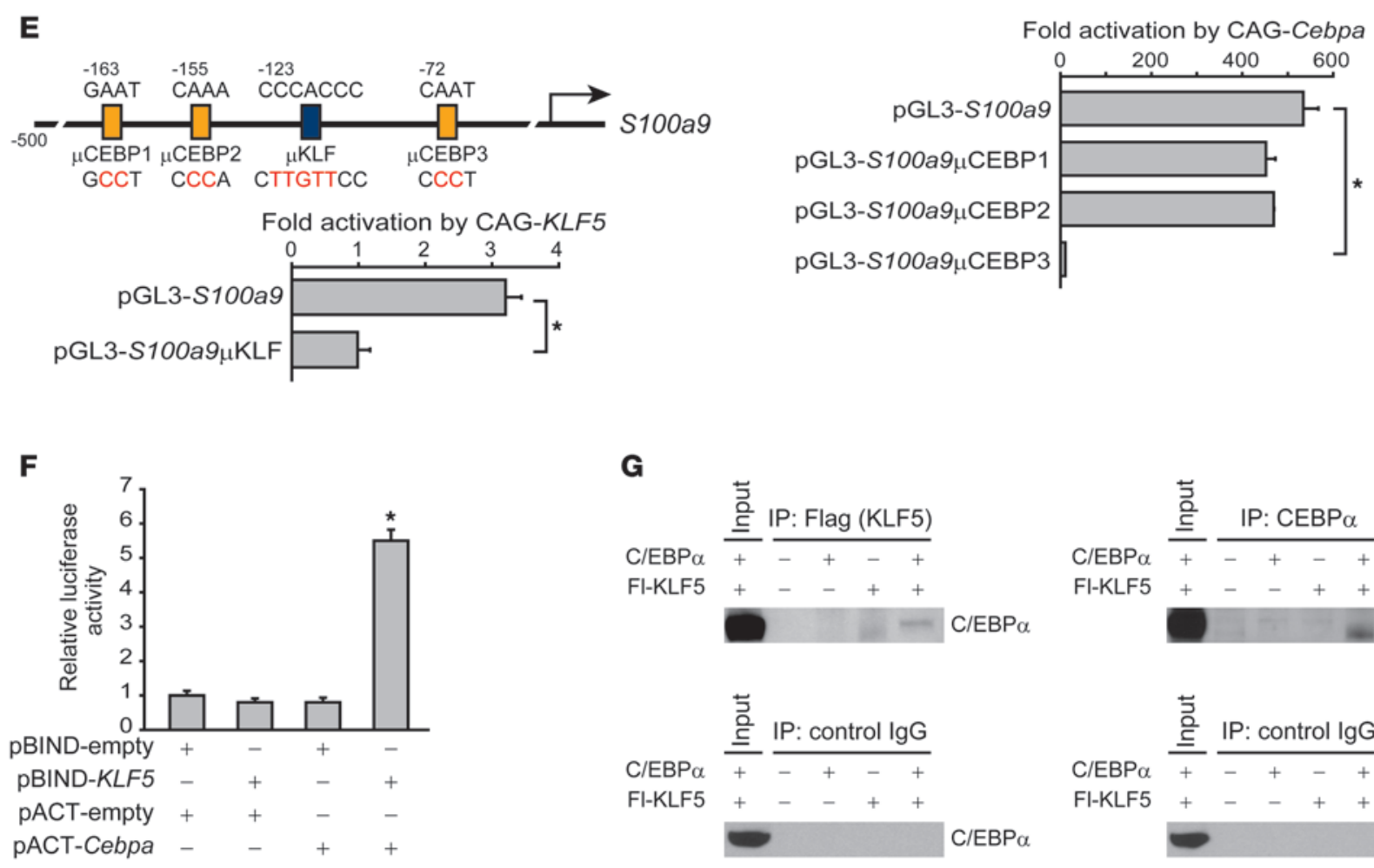

G

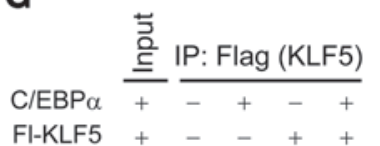

C/EBP $\alpha$

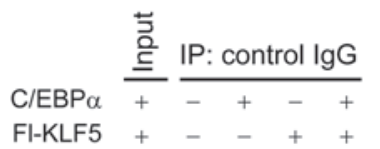

C/EBP $\alpha$

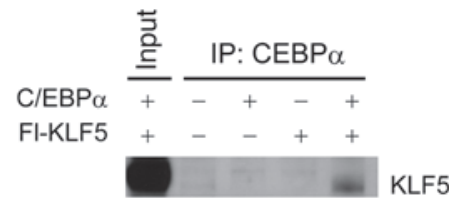

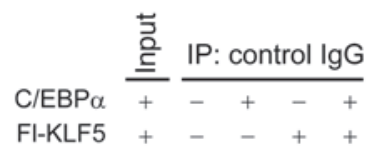




\section{Figure 9}

KLF5 transactivates the Cebpa, S100a8, and S100a9 promoters. (A) Expression of C/EBP $\alpha$ protein in mIMCD-3 cells infected with Adempty, Ad-LacZ, or Ad-KLF5. (B) Effects of KLF5 on the activity of the Cebpa proximal promoter. mIMCD3 cells were transfected with Cebpa promoter reporter constructs containing the indicated mutations within the putative KLF5-binding sites plus either an empty (CAG-empty) or KLF5-encoding (CAG-KLF5) plasmid. The luciferase activity of each reporter construct cotransfected with CAG-KLF5 was normalized to that of the reporter cotransfected with CAG-empty. Mutant sequences (indicated by $\mu$ ) are shown schematically. $n=6$. ${ }^{*} P<0.05$. (C) Effects of KLF5 and C/EBP $\alpha$ on S100a8 and S100a9 promoter activity. Luciferase reporters driven by the promoters were cotransfected with expression vectors for KLF5 and C/EBP $\alpha$ (CAG-Cepba), as indicated. Luciferase activity was normalized to that of the reporter construct cotransfected with CAG-empty. $n=6$. (D and E) Relative activation of mutant S100a8 and S100a9 promoters by KLF5 and C/EBP $\alpha$. Mutant sequences are shown schematically. $n=6$. ${ }^{*} P<0.05$. (F) Mammalian two-hybrid analysis of the interaction between KLF5 and C/EBP $\alpha$. mIMCD-3 cells were transfected with the indicated combinations of plasmids containing the Gal4-DNA binding domain fused to the fulllength KLF5 (pBIND-KLF5) and the VP16-activation domain fused to the full-length $\mathrm{C} / \mathrm{EBP} \alpha$ (pACT-Cebpa), along with a reporter plasmid (pG5-luc). $n=6 .{ }^{*} P<0.05$ versus cells transfected with pBIND-empty and pACT-empty. (G) Physical interaction between KLF5 and C/EBP $\alpha$. Lysates of mIMCD-3 cells expressing Flag-tagged KLF5 (FI-KLF5) and $\mathrm{C} / \mathrm{EBP} \alpha$ were immunoprecipitated with antibody against Flag, $\mathrm{C} / \mathrm{EBP} \alpha$, or control IgG. Immunoprecipitates were probed for C/EBP $\alpha$ or KLF5.

We next tested whether S100A8 and S100A9 might be capable of recruiting $\mathrm{CD} 11 \mathrm{~b}^{+} \mathrm{Ly}-6 \mathrm{C}^{+}$monocytes. S100A8/A9 injection resulted in accumulation of $\mathrm{CD} 11 \mathrm{~b}^{+} \mathrm{F} 4 / 80^{\mathrm{lo}} \mathrm{Ly}-6 \mathrm{C}^{+} \mathrm{CD} 301^{-}$cells (Figure $8 C)$. In contrast to UUO, S100A8/A9 injection did not induce M2type differentiation. Following the injection, expression of Emr1 and $I l 1 b$ was increased, while Csf1r expression was decreased (Supplemental Figure 12C), indicating M1-type macrophage differentiation of recruited inflammatory monocytes in the kidneys.

We also tested whether injection of S100A8/A9 might rescue the wild-type phenotype in $\mathrm{Klf5}^{+/-}$kidneys. We found that S100A8/A9 increased the $\mathrm{CD} 11 \mathrm{~b}^{+} \mathrm{F} 4 / 80^{\text {lo }}$ cell fractions in $\mathrm{Klf5}^{+/-}$kidneys to levels similar to those in wild-type kidneys, while decreasing the $\mathrm{CD} 11 \mathrm{~b}^{+} \mathrm{F} 4 / 80^{\text {hi }}$ cell fraction (Supplemental Figure 13A). In addition, S100A8/A9 increased apoptosis and tubular injury, while suppressing interstitial fibrosis (Supplemental Figure 13B). Likewise, renal injury scores in $\mathrm{KlF5}^{+/-}$kidneys were similar to those in wildtype kidneys after S100A8/A9 injection, indicating that S100A8 and S100A9 are the key mediators regulated by KLF5 in response to UUO. Taken together, these results demonstrate that S100A8 and S100A9, which are induced by KLF5 in response to UUO, recruit $\mathrm{CD}_{11} \mathrm{~b}^{+} \mathrm{Ly}-6 \mathrm{C}^{+}$inflammatory monocytes to the kidneys and promote their M1-type differentiation in the monocytes.

KLF5 acts in concert with C/EBPQ to control S100a8 and S100a9 expression. Previous in vitro studies suggest C/EBP transcription factors are involved in the control of $S 100 a 8$ and $5100 a 9$ transcription (38-40), but it is not yet clear whether C/EBP proteins regulate the promoters in vivo. Interestingly, overexpression of Klf5 led to increases in the expression of C/EBP $\alpha$ (Figure 9A and Supplemental Figure 14A), and ChIP-seq revealed that KLF5 binds to the Cebpa locus. Conversely, knocking down Klf5 reduced levels of the Cebpa transcript and C/EBP $\alpha$ protein in mIMCD-3 cells (Supplemental Figure 14, B and C), suggesting KLF5 directly controls Cebpa expression. Consistent with this idea, a reporter plasmid containing a fragment spanning -343 to +42 bp of the Cebpa promoter was transactivated by KLF5 (Figure 9B). Furthermore, the Cebpa promoter contains two potential KLF5 binding motifs, at -259 and at $-190 \mathrm{bp}$, and mutations within the motif at $-190 \mathrm{bp}$ abolished the KLF5-dependent transactivation.

We next conducted a series of reporter analyses to assess the functional involvement of KLF5 and C/EBP $\alpha$ in the transcriptional regulation of $S 100 a 8$ and $S 100 a 9$. We found that the $S 100 a 8$ and $S 100 a 9$ promoters were transactivated by either KLF5 or $\mathrm{C} / \mathrm{EBP} \alpha$ and that their coexpression led to synergistic activation of the promoters (Figure 9C). Mutations within the potential KLF5 binding sites abolished KLF5-dependent activation of the promoters (Figure 9, D and E). Similarly, among the potential $\mathrm{C} / \mathrm{EBP}$ binding sites, mutations within motifs at $-321 \mathrm{bp}$ of $5100 \mathrm{a} 8$ or -72 bp of $5100 a 9$ significantly suppressed transactivation by $\mathrm{C} / \mathrm{EBP} \alpha$. The synergistic transactivation of the S100a8 and S100a9 promoters by KLF5 and C/EBP $\alpha$ suggests the two transcription factors physically interact. Indeed, mammalian two-hybrid analysis showed that KLF5 and C/EBP $\alpha$ do interact during transcriptional regulation (Figure $9 \mathrm{~F}$ ), and coimmunoprecipitation assays showed that they physically associate with one another in mIMCD-3 cells (Figure 9G).

UUO switches KLF5 targets in vivo. To further characterize the transcriptional regulatory circuit, we used in vivo ChIP analyses to analyze the promoter binding of KLF5 and C/EBP $\alpha$. Cells were isolated from renal papillae 24 hours after either UUO or control sham operation. In the control cells, KLF5 did not bind to Cebpa, S100a8, or S100a9, but it did bind to the $C d b 1$ promoter (Figure 10A). This binding profile was reversed by UUO. Following UUO, KLF5 bound to the Cebpa, S100a8, and S100a9 promoters, but binding to $C d h 1$ was eliminated (Figure 10A). Correspondingly, whereas $\mathrm{C} / \mathrm{EBP} \alpha$ did not bind to the S100a8 or $\$ 100 a 9$ promoter in control cells, it was recruited to those promoters by UUO (Figure 10B).

We then used sequential ChIP (re-ChIP) to determine whether KLF5 and C/EBP $\alpha$ simultaneously bind to the same promoters. Chromatin samples were prepared from renal papillary cells 12 and 24 hours after UUO. UUO induced KLF5 binding to S100a8 and S100a9 within 12 hours, but C/EBP $\alpha$ was not bound to the promoters at that time (Figure 10, C and D). The chromatin samples pulled down by KLF5 or C/EBP $\alpha$ antibody were then further immunoprecipitated with C/EBP $\alpha$ or KLF5 antibody, respectively. These re-ChIP assays showed that while $\mathrm{C} / \mathrm{EBP} \alpha$ did not bind to the KLF5-bound S100a8 and S100a9 promoters 12 hours after UUO (Figure 10, C and D), both KLF5 and $\mathrm{C} / \mathrm{EBP} \alpha$ were bound to the promoter 24 hours after UUO. This strongly suggests that UUO induces KLF5 binding to the Cebpa, S100a8, and S100a9 promoters within 12 hours, and that the induction of Cebpa expression by KLF5 leads to cooperative transactivation of the S100a8 and S100a9 promoters by KLF5 and C/EBP $\alpha$. As would be expected from this model, renal levels of Klf5 transcript were increased within 4 hours after UUO, and this was followed by induction of Cebpa expression (Figure 11A). Levels of $S 100 a 8, S 100 a 9$, and Ccl2 transcripts were increased within 12 hours, and levels of KLF5, C/EBP $\alpha$, S100A8, and S100A9 proteins were clearly increased in whole kidneys 6-12 hours after UUO (Figure 11B). More specifically, KLF5, S100A8, and S100A9 proteins were increased in collecting duct cells 12 hours after UUO, but were undetectable in non-collecting duct cells (Figure 11C). As expected, levels of these mRNAs 

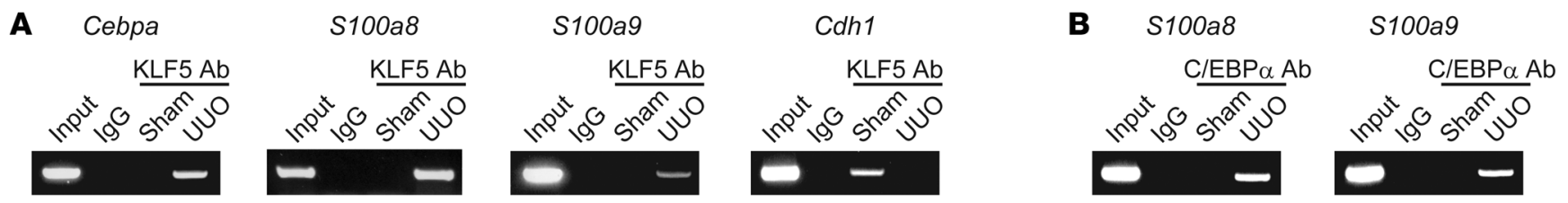

C $1^{\circ} \mathrm{ChIP}$

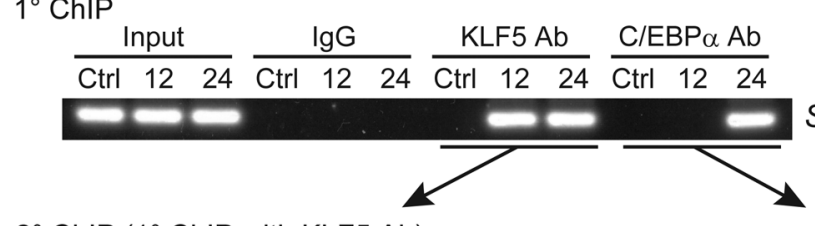

$2^{\circ} \mathrm{ChIP}\left(1^{\circ} \mathrm{ChIP}\right.$ with KLF5 Ab)

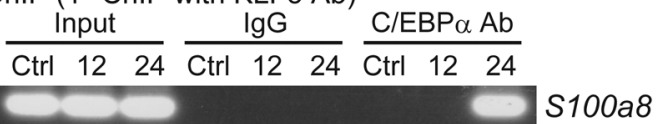

S100a8

$2^{\circ} \mathrm{ChIP}\left(1^{\circ} \mathrm{ChIP}\right.$ with KLF5 Ab)

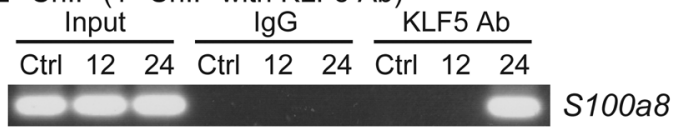

D $1^{\circ} \mathrm{ChIP}$

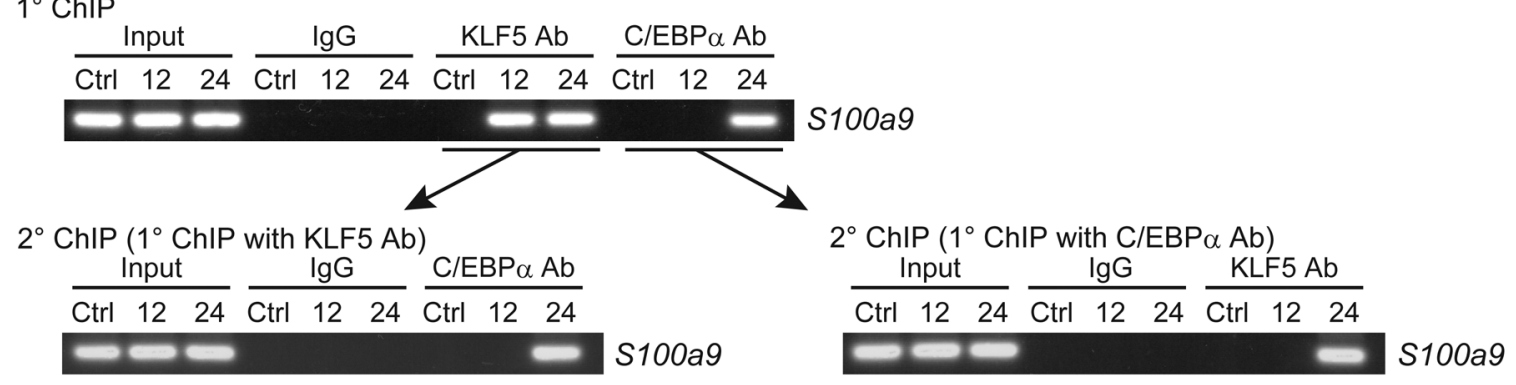

Figure 10

UUO alters KLF5 binding targets in vivo. (A and B) ChIP assays for KLF5 (A) and C/EBP $\alpha$ (B) binding to their target promoters in IMCD cells isolated from kidneys subjected to either UUO or sham operation. One percent of the input chromatin from IMCD cells isolated from the shamoperated kidneys was used as a positive control (Input). Samples prepared from UUO kidneys and immunoprecipitated with nonimmune IgG were used as a negative control. ChIP assays using a nontarget region (Pdgfa $3^{\prime} \mathrm{UTR}$ ) as a negative control are shown in Supplemental Figure 15A. (C and D) In vivo re-ChIP analysis of the simultaneous binding of KLF5 and C/EBP $\alpha$ to the S100a8 (C) and S100a9 (D) promoters. Chromatin samples prepared from renal papillary cells of control (Ctrl) and 12- and 24-hour UUO kidneys were subjected to immunoprecipitation using KLF5 or C/EBP $\alpha$ antibody ( $\left(1^{\circ} \mathrm{ChIP}\right)$. The immunoprecipitates were then pulled down further using C/EBP $\alpha$ or KLF5 antibody, respectively $\left(2^{\circ}\right.$ ChIP). ChIP assays of a nontarget region (Pdgfa 3'UTR) are shown in Supplemental Figure 15B.

and proteins were all reduced in $K l f 5^{+/-}$kidneys (Figure 11, A, $\mathrm{B}$, and D). By contrast, $\mathrm{CCl} 2$ expression only differed on days 4 and 7 (Figure 11A).

The binding of KLF5 to the Cdh1 promoter under basal conditions (Figure 10A) suggests KLF5 also regulates Cdh1 expression. That notion is supported by the observations that $C d h 1$ expression was reduced in $\mathrm{Klf5}^{+/-}$kidneys (Supplemental Figure 15C), that knocking down Klf5 reduced Cdh1 expression in mIMCD-3 cells (Supplemental Figure 15D), and that KLF5 transactivated the $C D H 1$ promoter (Supplemental Figure 15E). KLF5 thus appears to control $C d h 1$ expression under basal conditions, and UUO switches the KLF5 target genes from $C d b 1$ to Cebpa, S100a8, and S100a9.

KLF5 in renal collecting duct cells plays a central role in $\mathrm{CD} 11 b^{+} \mathrm{F} 4$ / $80^{l o}$ cell accumulation and renal damage. In the kidney, Klf5 is primarily expressed in renal collecting ductal cells (Figure 1, A-D, and Supplemental Figure 1C). However, occasional lowlevel KLF5 staining was observed in a few stromal cells, which could be fibroblasts and/or BMDCs. To further establish the importance of KLF5 expressed in collecting duct cells to renal injury, we carried out a set of BM transplantation experiments. When wild-type mice whose BM had been replaced with that from either wild-type or $\mathrm{Klf5}^{+/-}$mice subjected to UUO, the $\mathrm{CD} 11 \mathrm{~b}^{+} \mathrm{F} 4 / 80^{\text {lo }}$ fractions did not significantly differ between the two groups (Figure 12A), nor did levels of Klf5, Cebpa, S100a8, and S100a9 expression (Figure 12B) and renal injury scores (Supplemental Figure 16).

To further rule out a possible contribution of KLF5 in macrophages to the observed renal $\mathrm{Klf5}^{+/-}$phenotypes, we selectively ablated Klf5 in myeloid cells by crossing Klf5 floxed mice (Klf $5^{\text {ll/fl})}$ with LysM-Cre mice (41). As a result, more than $95 \%$ of Klf5 floxed alleles were deleted in kidney CD11 $\mathrm{b}^{+} \mathrm{F} 4 / 80^{+}$cells (Supplemental Figure 17A). This Klf5 deficiency in macrophages did not affect the accumulation of $\mathrm{CD} 11 \mathrm{~b}^{+} \mathrm{F} 4 / 80^{\mathrm{lo}}$ and $\mathrm{CD} 11 \mathrm{~b}^{+} \mathrm{F} 4 / 80^{\mathrm{hi}}$ cells in UUO kidneys or their expression of cytokines (Figure 7, A and B, and Supplemental Figure 17B). Moreover, renal injury scores were unaffected by myeloid-specific Klf5 deletion (Supplemental Figure 18).

To further confirm the importance of KLF5 expressed in 

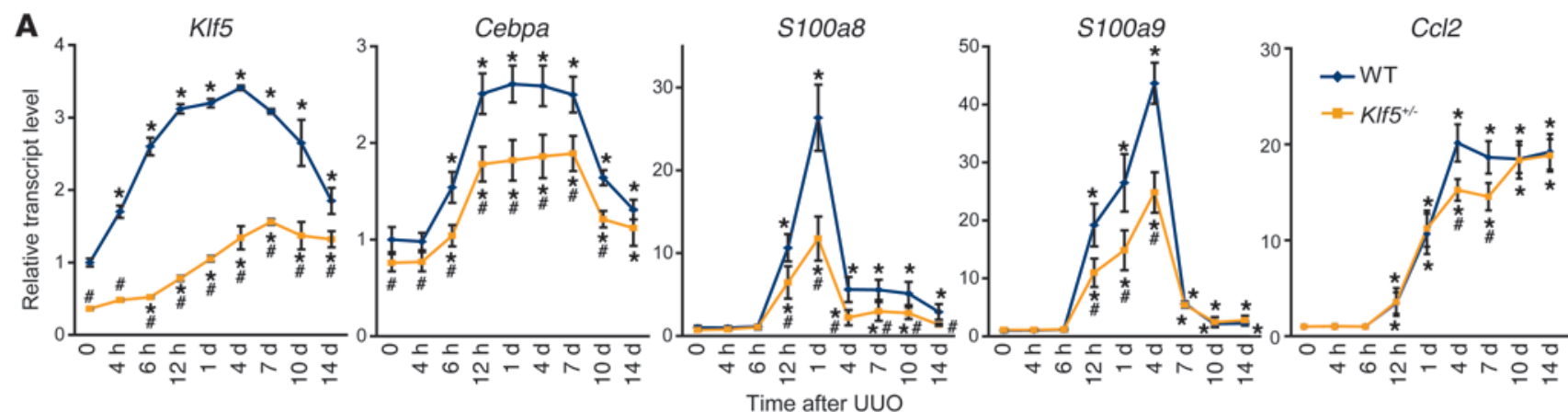

B
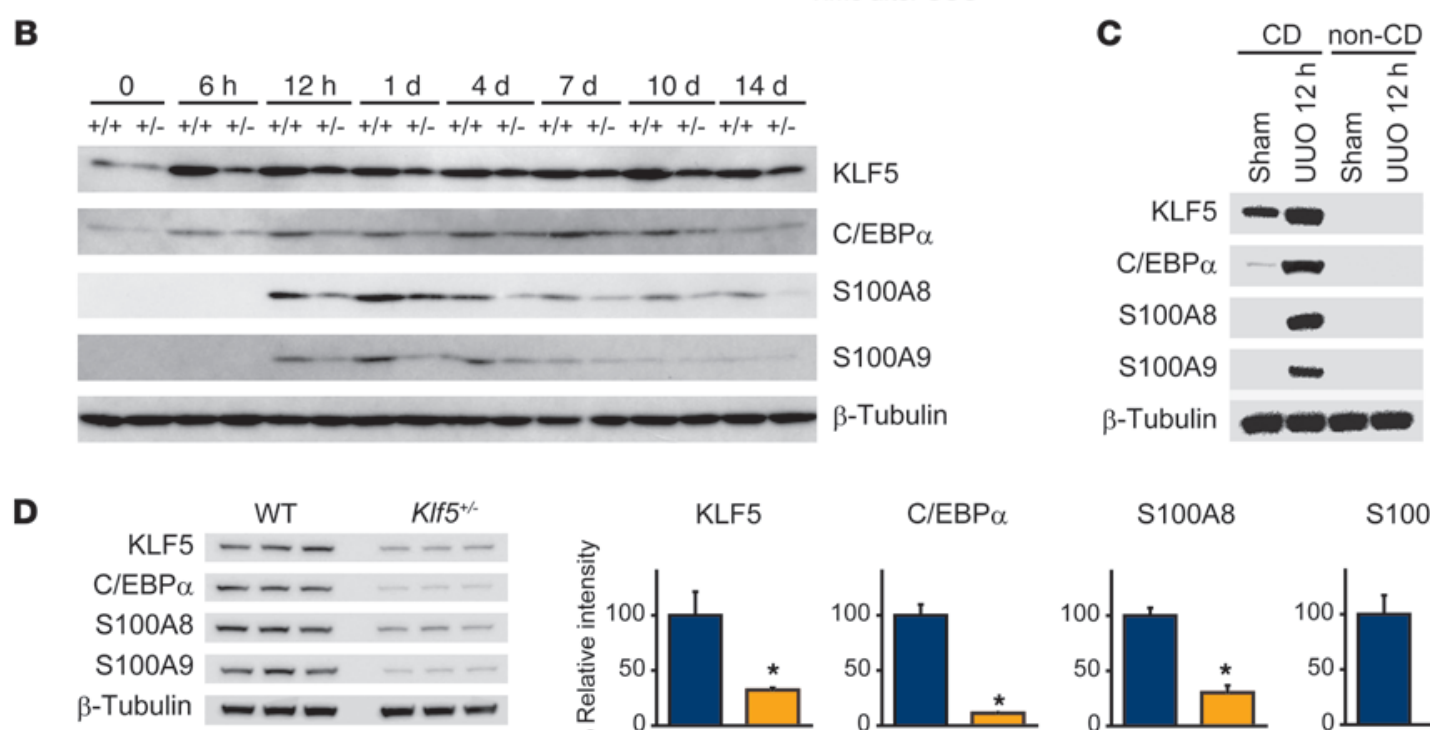

\section{Figure 11}

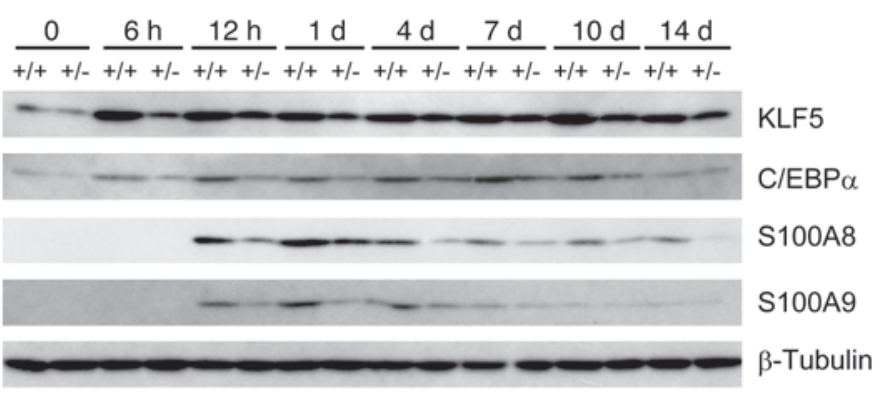

KLF5 is essential for induction of C/EBP $\alpha$ and S100A8/S100A9 in vivo. (A) Time course of KIf5, Cebpa, S100a8, S100a9, and Cc/2 expression in kidneys from wild-type and $K / f 5^{+/}$mice following UUO. Expression levels were normalized to those of $18 \mathrm{~s}$ rRNA and then further normalized to the levels in the control wild-type kidney. Data labeled 0 show gene expression in kidneys under basal conditions. $n=5$ for each group. ${ }^{*} P<0.05$ versus control kidneys of the same genotype; $P<0.05$ versus wild-type at the same time point. Note that some of the KIf5 expression data are the same as in Figure 3A. (B) Time course of KLF5, C/EBP $\alpha$, S100A8, and S100A9 protein expression after UUO in whole kidneys from wild-type (+/+) and $\mathrm{Klf5}^{+/-}(+/-)$mice. (C) Collecting duct-specific expression of KLF5, C/EBP $\alpha, \mathrm{S} 100 \mathrm{~A} 8$, and S100A9 12 hours after UUO. KLF5, C/EBP $\alpha, \mathrm{S} 100 \mathrm{~A} 8$, and S100A9 protein expression was analyzed in collecting duct (CD) and non-collecting duct (non-CD) cells prepared from sham-operated and 12-hour UUO kidneys. (D) Expression of KLF5, CEBP $\alpha$, S100A8, and S100A9 proteins in CD cells isolated from wild-type and $K / f 5^{+/-}$kidneys 1 day after UUO. Relative intensities of the bands analyzed by quantitative densitometry are shown. ${ }^{*} P<0.05$ versus wild-type. $n=3$.

the collecting duct, we selectively deleted Klf5 from collecting duct cells by crossing Klf $5^{f l / f l}$ mice with Aqp2-Cre mice in which Cre expression was selectively driven in collecting duct cells by the Aqp2 promoter (Supplemental Figure 19A). The efficacy of the Klf5 deletion from collecting duct cells was approximately 70\% (Supplemental Figure 19, B-D). Under basal conditions, Klf5 $5^{f / f l} ;$ Aqp2-Cre mice did not show abnormal kidney histology or blood chemistry (i.e., creatinine and electrolyte levels) (Supplemental Figure 19E and Supplemental Table 4). In kidneys from the collecting duct-specific Klf5-knockout mice, accumulation of $\mathrm{CD} 11 \mathrm{~b}^{+} \mathrm{F} 4 / 80^{\text {lo }}$ cells (Figure 12C) and expression of Klf5, Cebpa, S100a8, and S100a9 were significantly reduced, as compared with kidneys from $K l f 5^{f l / f l}$ mice, 24 hours after UUO (Figure 12D). The apoptotic cell fractions and glomerular sclerosis and tubular injury scores were all reduced in Klf5//ff; Aqp2-Cre mice, while interstitial fibrosis was enhanced, as compared with Klf5/f/fl mice (Supplemental Figure 18). Overall, the renal phenotypes of $\mathrm{Klf}^{5 / \mathrm{fl} / \mathrm{fl}}$;AqP2-Cre mice were largely comparable to those of $\mathrm{Klf5}^{+/-}$ mice, indicating that KLF5 expressed in collecting duct cells is primarily responsible for the renal phenotypes observed in $\mathrm{Klf5}^{+/-}$ mice and is essential for renal responses to UUO.

\section{Discussion}

The results of the present study demonstrate that renal collecting duct cells play a pivotal role in the response to renal injury (Figure 12E). In response to UUO, S100a 8 and S100a 9 expression is induced by KLF5. S100A8 and S100A9 in turn recruit CD11b $\mathrm{by}^{+} 6 \mathrm{C}^{+}$ inflammatory monocytes to the kidneys, and then contribute to the cells' differentiation into M1-type CD $11 \mathrm{~b}^{+} \mathrm{F} 4 / 80^{\mathrm{lo}}$ cells, which promote renal epithelial injury and inflammation. Thereafter, the numbers of $\mathrm{CD} 11 \mathrm{~b}^{+} \mathrm{F} 4 / 80^{\text {hi }} \mathrm{M} 2$-type cells, which promote fibrosis, gradually increase. As such, KLF5 is a pivotal regulator of the 
A
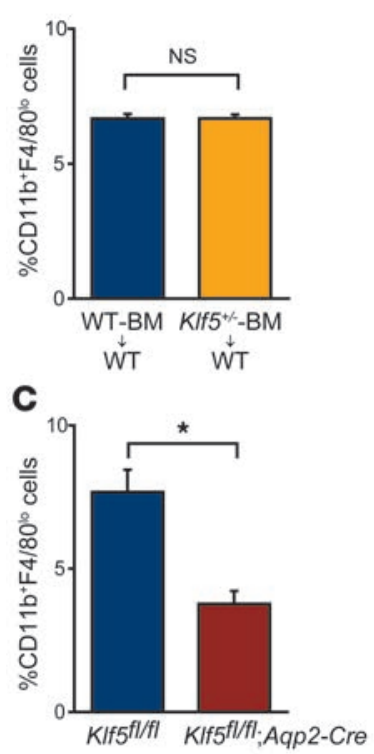

B
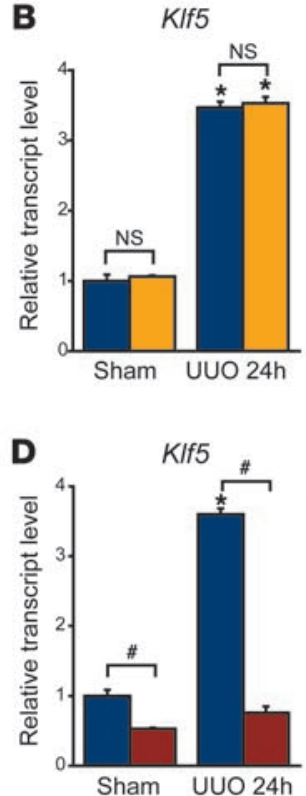

Cebpa

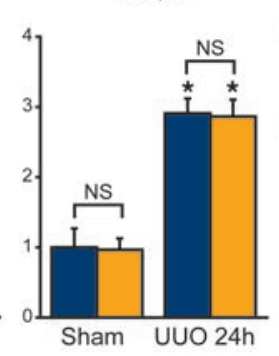

S100a8

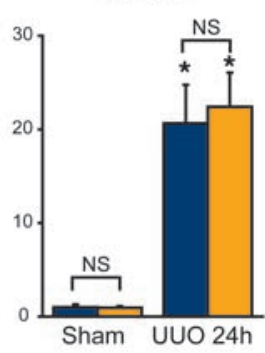

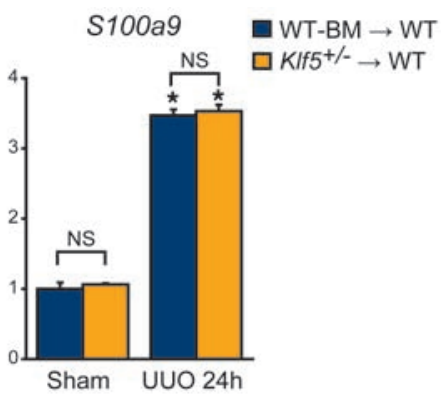
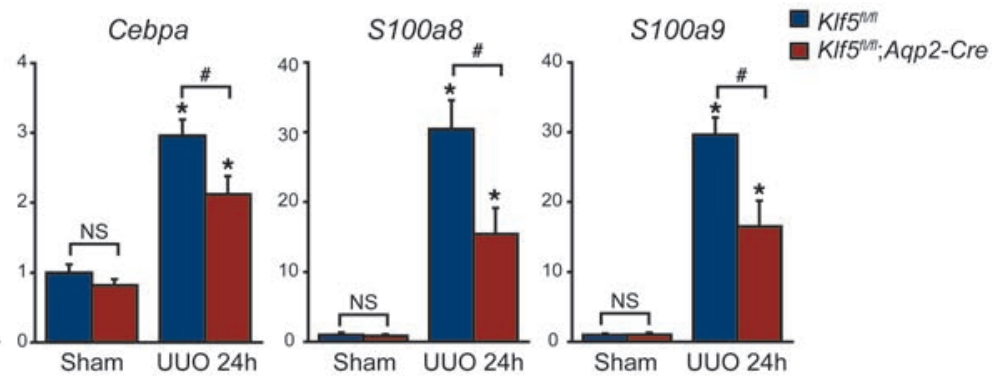

\section{E Collecting duct}

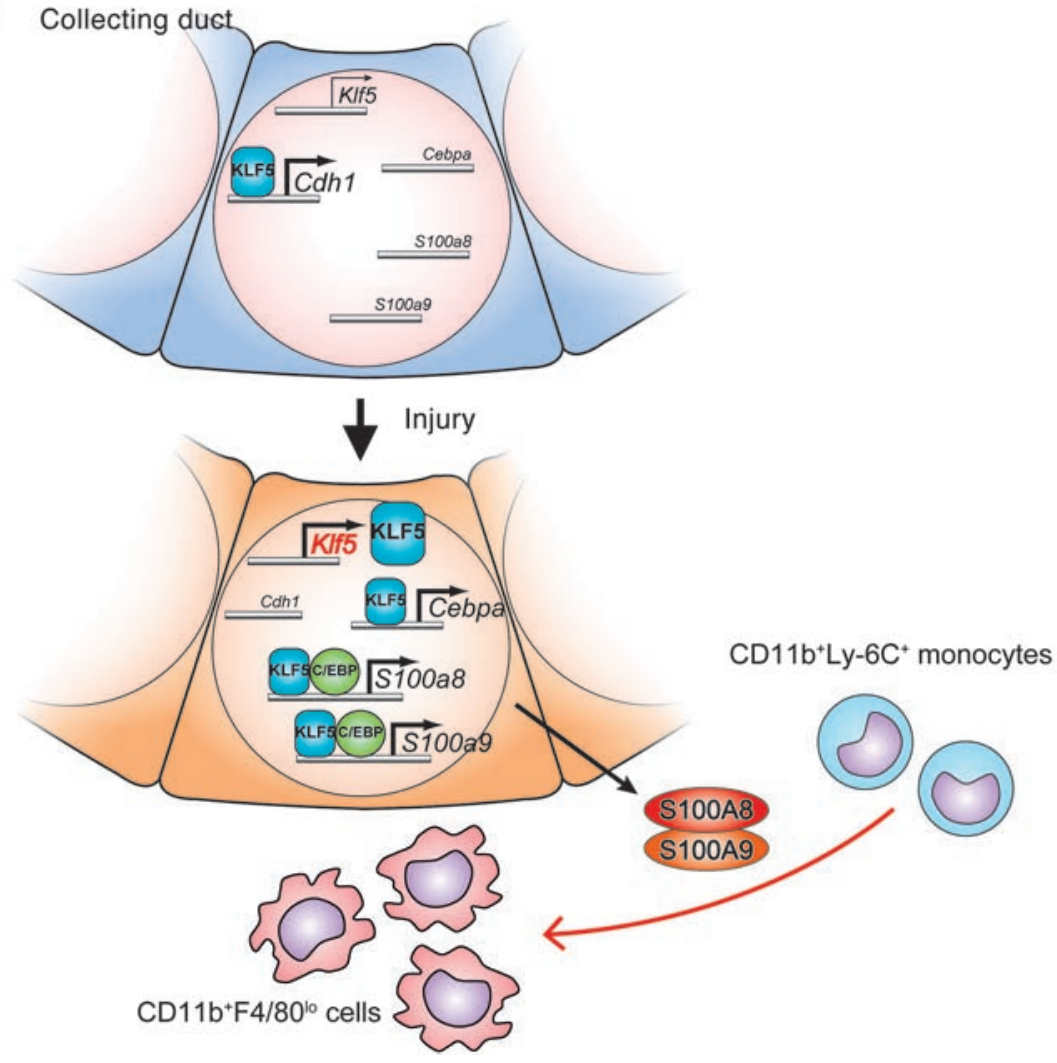

Figure 12

KLF5 in renal collecting duct cells controls renal responses to UUO. (A and $\mathbf{B}$ ) Effects of BM-specific KIf5 haploinsufficiency on the responses to UUO. Wild-type mice whose BM had been replaced with either wild-type or $\mathrm{Klf5}^{+/-} \mathrm{BM}$ were subjected to either UUO or sham operation. (A) $\mathrm{CD} 11 \mathrm{~b}^{+} \mathrm{F} 4 / 80^{\text {lo }}$ fractions were analyzed 24 hours after UUO. $n=5$. (B) mRNA expression was analyzed using real-time PCR 24 hours after UUO. Expression levels were normalized to those of $18 \mathrm{~s}$ rRNA and then further normalized to the levels in sham-operated mice transplanted with wild-type BM. $n=5$. ${ }^{*} P<0.05$ versus sham-operated mice transplanted with BM from the same genotype. (C and D) Effects of collecting duct-specific KIf5 deletion on the response to UUO. KIf $5^{f / f l}$ and KIff ${ }^{f / / f \mid} ;$ Aqp2-Cre mice were subjected to either $\mathrm{UUO}$ or sham operation. (C) CD11b+F4/80 lo fractions were analyzed 24 hours after UUO. $n=5$. ${ }^{*} P<0.05$. (D) mRNA expression was analyzed using real-time PCR 24 hours after UUO. Expression levels were normalized to those of 18s rRNA and then further normalized to the levels in shamoperated KIf5 fl/II mice. $n=5 .{ }^{*} P<0.05$ versus shamoperated mice of the same genotype; $P<0.05$. (E) A model of the KLF5-C/EBP $\alpha-S 100 A 8 / A 9$ pathway leading to renal inflammation. response of collecting duct cells to renal injury. Because KLF5 regulates early accumulation of CD $11 b^{+} \mathrm{Ly}-6 \mathrm{C}^{\text {lo }}$ cells in UUO kidneys, Klf5 haploinsufficiency and collecting duct-specific Klf5 deletion skewed macrophage differentiation toward M2, leading to amelioration of the renal injury but enhancement of the fibrosis.

Our identification of two $\mathrm{CD} 11 \mathrm{~b}^{+} \mathrm{F} 4 / 80^{+}$cell subpopulations with different gene expression profiles clearly demonstrates that renal inflammation involves at least two phenotypically different monocyte/macrophage subpopulations: CD11b ${ }^{+} \mathrm{F} 4 /$ $80^{\text {lo }}$ monocytes/macrophages showing M1-type activation and $\mathrm{CD} 11 \mathrm{~b}^{+} \mathrm{F} 4 / 80^{\mathrm{hi}} \mathrm{M} 2$-type macrophages. In addition, we found that these subpopulations differentially accumulate over the course of the response to UUO: on days 1-4 after UUO, macrophage activation was skewed to M1-type, but at later times it was shifted toward M2-type. Lin et al. recently identified subsets of macrophages in UUO kidneys based on the surface expression of Ly-6C (11). In 
their study, CD $11 b^{+}$Ly-6Chi immature macrophages exhibited M1-type activation, while CD $11 b^{+}$Ly- $6 C^{\text {lo }}$ macrophages showed the M2-type phenotype. The gene expression profiles and surface phenotypes observed in the present study strongly suggest that $\mathrm{CD} 11 \mathrm{~b}^{+} \mathrm{F} 4 / 80^{\mathrm{lo}}$ and $\mathrm{CD} 11 \mathrm{~b}^{+} \mathrm{F} 4 / 80^{\text {hi }}$ cells largely correspond to the CD $11 b^{+}$Ly-6C hi and CD $11 b^{+}$Ly-6C lo macrophages, respectively.

The results of the present study demonstrate that renal $\mathrm{CD} 11 \mathrm{~b}^{+} \mathrm{F} 4 / 80^{\text {lo }}$ and $\mathrm{CD} 11 \mathrm{~b}^{+} \mathrm{F} 4 / 80^{\text {hi }}$ cells differ functionally from one another. By showing that inflammatory $\mathrm{CD} 11 \mathrm{~b}^{+} \mathrm{F} 4 / 80^{\mathrm{lo}} \mathrm{M} 1-$ type cell accumulation was selectively suppressed in $\mathrm{Klf5}^{+/-}$mice and that tubular injury, cellular apoptosis, and proinflammatory cytokine expression were all diminished in $\mathrm{Klf5}^{+/-}$mice, the present study demonstrates that M1-type macrophages are crucially involved in the renal injury and inflammation caused by UUO. Our results also indicate that $\mathrm{CD} 11 \mathrm{~b}^{+} \mathrm{F} 4 / 80^{\mathrm{lo}}$ and $\mathrm{CD} 11 \mathrm{~b}^{+} \mathrm{F} 4 / 80^{\mathrm{hi}}$ cells differentially contribute to the renal response to injury, at least in part through production of different sets of cytokines. Interestingly, fibrosis was enhanced in $\mathrm{Klf5}^{+/-}$and $\mathrm{KlfS}^{f l / f l} ; \mathrm{Aqp} 2$-Cre mice, in which $\mathrm{CD} 11 \mathrm{~b}^{+} \mathrm{F} 4 / 80^{\mathrm{hi}} \mathrm{M} 2$-type macrophage accumulation was increased but accumulation of $\mathrm{CD} 11 \mathrm{~b}^{+} \mathrm{F} 4 / 80^{\text {lo }} \mathrm{M} 1$-type cells was reduced. This suggests that the skewed balance toward M2 activation in $\mathrm{Klf5}^{+/-}$mice led to the enhanced fibrosis. Histologically, however, interstitial fibrosis was apparent only on day 7; thereafter, differences in the M1/M2 ratio were no longer observed between wild-type and $\mathrm{Klf5}^{+/-}$kidneys (Figure 4B). Nonetheless, expression levels of genes involved in fibrosis, including Col3a1, Fn1, Vim, and $\mathrm{Tg} f \mathrm{bl}$, were significantly increased from day 4 in $\mathrm{Klf5}^{+/-}$kidneys (Figure 3B). The activation of fibrotic processes therefore appears to coincide with increases in the M2-type cell fractions in $\mathrm{Klf5}^{+/-}$ kidneys. These findings suggest that the renal environment (e.g., skewed balance toward M2 activation, reduced expression of proinflammatory cytokines, and increased expression of TGF- $\beta 1$ ) at early times after UUO (up to day 7) alters inflammatory processes and affects the later fibrotic phenotype. This idea is supported by our finding that on day 7 levels of $I l 1 b$ and $C c l 2$ expression were

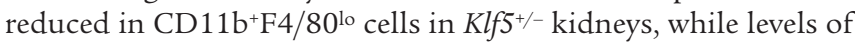
$\mathrm{Tg} f 1 b$ and $I l 10$ expression were increased in $\mathrm{CD} 11 \mathrm{~b}^{+} \mathrm{F} 4 / 80^{\text {hi }}$ cells (Figure 7). The finding that injection of $\mathrm{Klf5}^{+/-}$mice with S100A8 or S100A9 not only skewed the monocyte/macrophage balance toward $\mathrm{CD} 11 \mathrm{~b}^{+} \mathrm{F} 4 / 80^{\mathrm{lo}} \mathrm{M} 1$-type cells but also suppressed interstitial fibrosis (Supplemental Figure 13) also supports the model.

In earlier studies, the same renal $\mathrm{CD} 11 \mathrm{~b}^{+}$mononuclear cell populations were identified variously as macrophages or DCs. In the present study, we refer to $\mathrm{CD} 11 \mathrm{~b}^{+} \mathrm{F} 4 / 80^{\mathrm{hi}}$ cells as macrophages because they clearly differ from classical DCs in the following ways: (a) CD11c levels are lower and F4/80 levels are higher than in classical DCs; (b) CD83 expression is absent; (c) they have a macrophage-like morphology; and (d) they can be differentiated from inflammatory monocytes (11). Similarly, Lin et al. referred to $\mathrm{CD} 11 \mathrm{~b}^{+} \mathrm{Ly}-6 \mathrm{C}^{\text {lo }}$ cells as macrophages $(11)$, though other groups have identified populations of kidney CD $11 b^{+}$cells as DCs. For example, $\mathrm{Li}$ et al. referred to resident $\mathrm{CD} 11 \mathrm{~b}^{+} \mathrm{F} 4 / 80^{\mathrm{hi}}$ cells as DCs, based on the intermediate expression of CD11c and other DC markers, including MHCII and CD86 (27). Dong et al. identi-

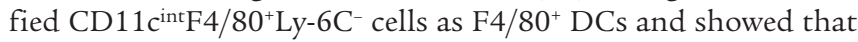
the population is increased in UUO kidneys (42). And Heymann et al. described CD $11 \mathrm{c}^{\text {int }} \mathrm{CD} 11 \mathrm{~b}^{\mathrm{int}}$ cells as resident DCs in mouse glomerulonephritis modes (43). Although the precise relationships between these cells are difficult to define due to a lack of the common reference cells (e.g., spleen cells) and differences in the flow cytometric methods used, $\mathrm{CD} 11 \mathrm{~b}^{+} \mathrm{F} 4 / 80^{\mathrm{hi}}$ cells, or at least subpopulations of them, appear to overlap previously identified kidney DCs. It has been difficult to clearly distinguish between macrophages and DCs, as these closely related cells share both phenotypical and functional characteristics particularly during inflammation (44). No single marker can unambiguously distinguish DCs from macrophages, and CD11c, which has been extensively used to identify DCs, is widely expressed in macrophages. Moreover, the capacity to present antigens to T cells, which is a characteristic of DCs, has also been seen in macrophages (31). Consequently, the same cell populations in various tissues have been identified as either DCs or macrophages. In particular, whether $\mathrm{CD} 11 \mathrm{c}^{+}$cells derived from circulating monocytes should be classified as DCs is a matter of debate $(31,44)$. In the small intestine, for instance, in addition to CD $11 c^{\text {hi }} C D 11 b^{+} C D 103^{+} C X 3 C R 1^{-}$bona fide DCs, there are $\mathrm{Ly}-6 \mathrm{c}^{\mathrm{hi}}$ monocyte-derived CD $11 \mathrm{c}^{\text {int }} \mathrm{CD} 11 \mathrm{~b}^{+} \mathrm{CD} 103^{-} \mathrm{CX} 3 \mathrm{CR} 1^{+}$cells, which appear to share at least some phenotypes with renal $\mathrm{CD} 11 \mathrm{~b}^{+} \mathrm{F} 4 / 80^{\mathrm{hi}}$ cells (27) and are considered by some researchers to be DCs $(34,45)$. However, intestinal CX3CR $1^{+}$cells do not migrate into draining mesenteric lymph nodes or efficiently present antigens to $\mathrm{T}$ cells (46). These characteristics of intestinal CX3CR1 ${ }^{+}$cells are indistinguishable from those of tissue macrophages (44). Clearly, further study of the lineages and functions, including migratory capacity, of kidney CD11 $b^{+}$cells will be needed to determine whether they should be classified as macrophages or DCs.

Renal CD11 $\mathrm{c}^{\text {hi }} \mathrm{MHCII}{ }^{+} \mathrm{CD} 83^{+} \mathrm{CD}_{11 b^{-}}$cells closely resemble splenic classical DCs phenotypically and morphologically. An earlier study identified $\mathrm{CD} 11 \mathrm{c}^{+} \mathrm{CD} 103^{+} \mathrm{MHCII}{ }^{+} \mathrm{CD} 11 \mathrm{~b}^{-}$cells in kidneys as CD $103^{+}$DCs (47), and those cells might be related to the CD11 $\mathrm{c}^{\text {hi }}$ cells identified in the present study. However, additional studies of the function and lineage of these cells will be needed before they can be classified as renal classical DCs.

The surface phenotypes of $\mathrm{CD}_{1} 1 \mathrm{~b}^{+} \mathrm{F} 4 / 80^{\text {lo }}$ cells (e.g., CD $\left.11 \mathrm{c}^{\text {lo }} \mathrm{MHCII}^{-/+}{ }^{+} \mathrm{CD} 86^{-} \mathrm{CD}^{-} 3^{-}\right)$, their morphology, and the fact that they derive from inflammatory monocytes all strongly suggest they are macrophages and monocytes in the process of differentiating into macrophages. However, these cells might also have been identified as inflammatory DCs in some studies (42). In addition, we found that a minor population of $\mathrm{CD} 11 \mathrm{~b}^{+} \mathrm{F} 4 / 80^{\text {lo }}$ cells showed higher levels of CD11c and MHCII, particularly in normal and day-7 UUO kidneys (Supplemental Figure 6). Given that inflammatory monocytes can differentiate into $\mathrm{CD} 11 \mathrm{~b}^{+} \mathrm{F} 4 /$ $80^{\text {hi }}$ cells as well as CD $11 b^{+} \mathrm{F} 4 / 80^{\text {lo }}$ cells (Supplemental Figure 12 and ref. 11), they may represent intermediary cells differentiating into $\mathrm{CD} 11 \mathrm{~b}^{+} \mathrm{F} 4 / 80^{\mathrm{hi}} \mathrm{M} 2$-type cells. Future studies should address the differentiation pathways of inflammatory monocytes within kidneys and identify markers with which to trace them.

S100A8 and S100A9 are calcium-binding secretory proteins that can form homodimers and heterodimers, with the latter being more prevalent $(48,49)$. We found that levels of S100a8 and S100a9 expression peaked on days 1 and 4, respectively, after UUO (Figure $11 \mathrm{~A})$, at a time when $\mathrm{CD} 11 \mathrm{~b}^{+} \mathrm{F} 4 / 80^{\text {lo }}$ cells were accumulating within the kidneys (Figure 4B), which suggests S100A8 and S100A9 are essential for inflammatory $\mathrm{CD} 11 \mathrm{~b}^{+} \mathrm{F} 4 / 80^{\text {lo }}$ cell accumulation early in the response to UUO. We also found that adoptively transferred $\mathrm{CD} 11 \mathrm{~b}^{+}$Ly- $6 \mathrm{C}^{+}$inflammatory monocytes were recruited to kidneys following S100A8/A9 injection, and that the recruited cells exhibited the $\mathrm{CD} 11 \mathrm{~b}^{+} \mathrm{F} 4 / 80^{\mathrm{lo}} \mathrm{Ly}-6 \mathrm{C}^{+} \mathrm{CD} 206^{-} \mathrm{CD} 301^{-}$M1-type phenotype (Figure 8C). S100A8 and S100A9 were also capable of inducing M1 markers in BMDMs (Figure 8A). Collectively, these results demon- 
strate that S100A8 and S100A9 are important for the recruitment of inflammatory monocytes and their subsequent differentiation into M1-type macrophages during the early response to UUO.

That the accumulation of $\mathrm{CD} 11 \mathrm{~b}^{+} \mathrm{F} 4 / 80^{\text {hi }}$ cells begins 4 days after UUO suggests the renal microenvironment only becomes supportive of M2 activation at later times. Consistent with this idea, we found that only a minor population of CD $11 \mathrm{~b}^{+} \mathrm{Ly}-6 \mathrm{C}^{+}$monocytes acquires the M2-type phenotype when transferred prior to UUO, whereas Lin et al. showed that when transferred 5 days after UUO, major populations of $\mathrm{CD} 11 \mathrm{~b}^{+} \mathrm{Ly}-6 \mathrm{C}^{+}$monocytes exhibit the M2type phenotype (11). Because S100A8/A9 expression declines, it is likely that other cytokines recruit monocytes to kidneys at later times after UUO. MCP-1 (CCL2) is one candidate chemokine for such later recruitment (Figure 11A). Although we favor a model in which proinflammatory monocytes differentiate into at least two types of macrophages in response to the kidney microenvironment, the fact that monocytes appear to be recruited by different signals at different times suggests there are multiple subsets CD $11 \mathrm{~b}^{+} \mathrm{Ly}-6 \mathrm{C}^{+}$ inflammatory monocytes that are differentially recruited to kidneys and might differ in the direction of their differentiation (25).

The results obtained with $K l f^{f / / f l} ; A q p 2$-Cre mice demonstrate that expression of KLF5 in collecting duct epithelial cells is essential for the renal response to UUO. However, KLF5 might also have functions in other cell types, including macrophages and fibroblasts. Results obtained after transplantation of $\mathrm{Klf5}^{+/-} \mathrm{BM}$ and in $\mathrm{Klf5} 5^{f / f l} ; \mathrm{Ly}$ sM-Cre mice indicate that, even if KLF5 were functionally active in macrophages, its cell-autonomous function in macrophages would not be important for the renal $\mathrm{Klf5}^{+/-}$phenotypes. Indeed, the reduced expression of $\mathrm{Il} 1 \mathrm{~b}$ and $\mathrm{Ccl} 2$ in $\mathrm{CD} 11 \mathrm{~b}^{+} \mathrm{F} 4 / 80^{\text {lo }}$ cells and increased expression of $\mathrm{Tg} f b 1$ and $\mathrm{Il} 10$ in $\mathrm{CD} 11 \mathrm{~b}^{+} \mathrm{F} 4 / 80^{\text {hi }}$ cells in $\mathrm{Klf5}^{+/-}$mice, but not Klf5//fl; $L y s M$-Cre mice (Figure 7, A and B), is indicative of the importance of cell non-cell-autonomous effects on macrophage activation in $\mathrm{Klf5}^{+/-}$kidneys. Fibroblasts are another important cell type involved in mediating tubulointerstitial damage, and we previously showed that KLF5 expressed in cardiac fibroblasts is important for the cardiac responses to pressure overload (18). In kidneys the level of Klf5 expression in $\alpha$-SMA ${ }^{+}$myofibroblasts, mesangial cells, and smooth muscle cells was significantly lower than in cardiac fibroblasts (Supplemental Figure 1C). Moreover, if the functions of KLF5 in renal fibroblasts are similar to those in cardiac fibroblasts, Klf5 haploinsufficiency in renal fibroblasts would reduce fibrosis. It is therefore unlikely that cell-autonomous alterations of fibroblast function due to Klf5 haploinsufficiency make a major contribution to the renal $\mathrm{Klf5}^{+/-}$phenotypes. The results of the present study thus indicate that the observed renal $\mathrm{Klf5}^{+/-}$phenotypes primarily reflect Klf5 haploinsufficiency in the collecting duct.

Our data show that collecting duct epithelial cells are the major sensor of stress elicited by UUO. One important question remaining is, what do those cells sense? Given that Klf5 expression was increased within 4 hours after UUO, and KLF5 bound to the S100a 8 and S100a9 promoters within 12 hours, at a time when structural changes were minimal, it is very unlikely that pelvic dilation is the cause. One attractive candidate is mechanical force. After UUO there is a sudden rise in ureteric and intrarenal pressure, which translates into tubular mechanical stretch (50). Although very little is known about the effects of mechanical stretch on collecting duct epithelial cells, mechanical stretch is known to profoundly affect the function in various cell types (51). On the other hand, many other factors, including proteinuria, hypoxia, oxidative stress, and glomerulus-derived cytokines, likely contribute to activation of collecting duct cells (3). In that regard, we recently found that reactive oxygen species induce Klf5 expression in smooth muscle cells (52). Much work will be needed to clarify the mechanism by which collecting duct epithelial cells are activated under various disease conditions. Nevertheless, the results of the present study clearly indicate that the collecting duct is an essential regulator of inflammatory processes in the kidney, and the molecular mechanism identified in the present study may provide attractive targets for novel therapeutic strategies.

\section{Methods}

Mice. Male C57BL6/6J mice were purchased from CLEA Japan and maintained on a standard mouse chow diet. Klf5 $5^{+/-}$and $K l f 5^{f / / f l}$ mice were generated as described previously $(17,18)$. Aqp2-Cre mice were purchased from The Jackson Laboratory. UUO was performed as described previously (53). For BM transplantation, 8-week-old mice were lethally irradiated, and the next day unfractionated BM cells were administered to each recipient mouse. See Supplemental Methods for details. For renal function analysis, reversible UUO was performed (22). Briefly, 12-weekold mice were anesthetized and the right ureter was then ligated. After 3 days the right ureter ligation was removed, and the mice were allowed to recover for 7 days before the left ureter was ligated. All experiments were approved by the University of Tokyo Ethics Committee for Animal Experiments and strictly adhered to the guidelines for animal experiments of the University of Tokyo.

Flow cytometric analysis. The methods used to prepare cells from kidneys were described previously (54). All flow cytometric analyses were performed using a FACScalibur (BD) and FlowJo software (Tree Star). Cells were sorted using a FACSaria II (BD). See Supplemental Methods for details.

ChIP assays. ChIP assays were carried out as described previously (19). ChIP-seq was performed by sequencing the immunoprecipitated DNA using a 454 sequencer (Roche Diagnostics), after which the sequence reads were mapped to the reference mouse genome. See Supplemental Methods for details of in vivo ChIP and re-ChIP assays.

Infusion of recombinant proteins into kidney. Human recombinant S100A8 and A100A9 were purchased from ProtEra and dissolved in PBS $(0.5 \mathrm{mg} / \mathrm{ml})$. The LPS level in the mixed S100A8 and S100A9 solution was analyzed using a limulus amoebocyte lysate assay (Seikagaku Biobusiness Corp.). As solution of LPS in PBS in which the LPS concentration was matched to that in the S100A8/A9 solution $(0.092 \mathrm{EU} / \mathrm{ml})$ served as a control. An isotonic solution of glucose in PBS and PBS alone were also used as controls. A mixture of S100A8 and S100A9 (25 $\mu$ g each) was injected into the parenchyma of the left kidney without vascular clamping. The total injected volume for one kidney was $50 \mu \mathrm{l}$.

Statistics. Comparisons between 2 groups were made using Student's $t$ test (2-tailed). Differences among more than 2 groups were analyzed using 1-way ANOVA followed by Bonferroni (3 groups) or Tukey-Kramer post hoc (> 4 groups) tests. $P$ values less than 0.05 were considered significant. Error bars represent SD except where otherwise indicated.

\section{Acknowledgments}

We gratefully acknowledge M. Hayashi, N. Yamanaka, A. Ono, X. Yingda, Y. Tani, and E. Magoshi for their excellent technical assistance. We would like to thank Carey Lumeng for valuable discussion. This study was supported in part by the Funding Program for World-Leading Innovative R\&D on Science and Technology (FIRST Program) from the Japan Society for the Promotion of Science (to R. Nagai); grants-in-aid from the Ministry of Education, Culture, Sports, Science and Technology, Japan (to R. Nagai, I. Manabe, and 
K. Fujiu); a grant for Translational Systems Biology and Medicine Initiative from the Ministry of Education, Culture, Sports, Science and Technology of Japan and a research grant from the National Institute of Biomedical Innovation (to R. Nagai); and research grants from the Japan Science and Technology Institute, the Sumitomo Foundation, Takeda Science Foundation, the Mochida Memorial Foundation for Medical and Pharmaceutical Research, and the Mitsubishi Pharma Research Foundation (to I. Manabe).
Received for publication February 14, 2011, and accepted in revised form June 8, 2011.

Address correspondence to: Ichiro Manabe or Ryozo Nagai, Department of Cardiovascular Medicine, University of Tokyo, 7-3-1, Hongo, Bunkyo, Tokyo 113-8655, Japan. Phone: 81.3.3815.6672; Fax: 81.3.3818.6673; E-mail: manabe-tky@umin. ac.jp (I. Manabe), nagai-tky@umin.ac.jp (R. Nagai).
1. Harris RC, Neilson EG. Toward a unified theory of renal progression. Annu Rev Med. 2006;57:365-380.

2. Chevalier RL, Forbes MS, Thornhill BA. Ureteral obstruction as a model of renal interstitial fibrosis and obstructive nephropathy. Kidney Int. 2009;75(11):1145-1152.

3. Sean Eardley K, Cockwell P. Macrophages and progressive tubulointerstitial disease. Kidney Int. 2005;68(2):437-455.

4. Schnaper HW, Kopp JB. Why kidneys fail: report from an American Society of Nephrology advances in research conference. J Am Soc Nephrol. 2006; 17(7):1777-1781.

5. Kluth DC, Erwig L-P, Rees AJ. Multiple facets of macrophages in renal injury. Kidney Int. 2004;66(2):542-557.

6. Ricardo SD, van Goor H, Eddy AA. Macrophage diversity in renal injury and repair. J Clin Invest. 2008;118(11):3522-3530.

7. Kluth DC. Pro-resolution properties of macrophages in renal injury. Kidney Int. 2007;72(3):234-236.

8. Duffield JS, et al. Selective depletion of macrophages reveals distinct, opposing roles during liver injury and repair. J Clin Invest. 2005;115(1):56-65.

9. Mosser DM, Edwards JP. Exploring the full spectrum of macrophage activation. Nat Rev Immunol. 2008;8(12):958-969.

10. Mantovani A. Macrophage diversity and polarization: in vivo veritas. Blood. 2006;108(2):408-409.

11. Lin SL, Castano AP, Nowlin BT, Lupher ML Jr, Duffield JS. Bone marrow Ly6Chigh monocytes are selectively recruited to injured kidney and differentiate into functionally distinct populations. J Immunol. 2009;183(10):6733-6743.

12. Fenton RA, Knepper MA. Mouse models and the urinary concentrating mechanism in the new millennium. Physiol Rev. 2007;87(4):1083-1112.

13. Ivanova L, Butt MJ, Matsell DG. Mesenchymal transition in kidney collecting duct epithelial cells. Am J Physiol Renal Physiol. 2008;294(5):F1238-F1248.

14. Smith JP, Pozzi A, Dhawan P, Singh AB, Harris RC. Soluble HB-EGF induces epithelial-tomesenchymal transition in inner medullary collecting duct cells by upregulating Snail-2. Am J Physiol Renal Physiol. 2009;296(5):F957-F965.

15. Butt MJ, Tarantal AF, Jimenez DF, Matsell DG. Collecting duct epithelial-mesenchymal transition in fetal urinary tract obstruction. Kidney Int. 2007;72(8):936-944.

16. Haldar SM, Ibrahim OA, Jain MK. Kruppel-like factors (KLFs) in muscle biology. J Mol Cell Cardiol. 2007;43(1):1-10.

17. Shindo T, et al. Kruppel-like zinc-finger transcription factor KLF5/BTEB2 is a target for angiotensin II signaling and an essential regulator of cardiovascular remodeling. Nat Med. 2002;8(8):856-863.

18. Takeda $\mathrm{N}$, et al. Cardiac fibroblasts are essential for the adaptive response of the murine heart to pressure overload. J Clin Invest. 2010;120(1):254-265.

19. Fujiu K, et al. Synthetic retinoid Am80 suppresses smooth muscle phenotypic modulation and instent neointima formation by inhibiting KLF5. Circ Res. 2005;97(11):1132-1141.

20. Nelson RD, et al. Expression of an AQP2 Cre recombinase transgene in kidney and male repro- ductive system of transgenic mice. Am J Physiol Cell Physiol. 1998;275(1 pt 1):C216-C226.

21. Bascands JL, Schanstra JP. Obstructive nephropathy: insights from genetically engineered animals. Kidney Int. 2005;68(3):925-937.

22. Puri TS, et al. Chronic kidney disease induced in mice by reversible unilateral ureteral obstruction is dependent on genetic background. Am J Physiol Renal Physiol. 2010;298(4):F1024-F1032.

23. Medzhitov R. Origin and physiological roles of inflammation. Nature. 2008;454(7203):428-435.

24. Zhu B, et al. CD $11 \mathrm{~b}+\mathrm{Ly}-6 \mathrm{C}$ (hi) suppressive monocytes in experimental autoimmune encephalomyelitis. J Immunol. 2007;179(8):5228-5237.

25. Swirski FK, et al. Ly-6Chi monocytes dominate hypercholesterolemia-associated monocytosis and give rise to macrophages in atheromata. J Clin Invest. 2007;117(1):195-205.

26. Geissmann F, Manz MG, Jung S, Sieweke MH, Merad M, Ley K. Development of monocytes, macrophages, and dendritic cells. Science. 2010;327(5966):656-661.

27. Li L, et al. The chemokine receptors CCR2 and CX3CR1 mediate monocyte/macrophage trafficking in kidney ischemia-reperfusion injury. Kidney Int. 2008;74(12):1526-1537.

28. Krüger T, et al. Identification and functional characterization of dendritic cells in the healthy murine kidney and in experimental glomerulonephritis. J Am Soc Nephrol. 2004;15(3):613-621.

29. Dong X, Swaminathan S, Bachman LA, Croatt AJ, Nath KA, Griffin MD. Resident dendritic cells are the predominant TNF-secreting cell in early renal ischemia-reperfusion injury. Kidney Int. 2007;71(7):619-628.

30. Hochheiser K, Tittel A, Kurts C. Kidney dendritic cells in acute and chronic renal disease. Int J Exp Pathol. 2011;92(3):193-201.

31. Hume DA. Macrophages as APC and the dendritic cell myth. J Immunol. 2008;181(9):5829-5835.

32. Prechtel A, Steinkasserer A. CD83: an update on functions and prospects of the maturation marker of dendritic cells. Arch Dermatol Res. 2007;299(2):59-69.

33. Vakkila J, Lotze MT, Riga C, Jaffe R. A basis for distinguishing cultured dendritic cells and macrophages in cytospins and fixed sections. Pediatr Dev Pathol. 2005;8(1):43-51.

34. Pabst O, Bernhardt G. The puzzle of intestinal lamina propria dendritic cells and macrophages. Eur J Immunol. 2010;40(8):2107-2111.

35. Liu Y, et al. Unique expression of suppressor of cytokine signaling 3 is essential for classical macrophage activation in rodents in vitro and in vivo. J Immunol. 2008;180(9):6270-6278.

36. Vandal K, Rouleau P, Boivin A, Ryckman C, Talbot $\mathrm{M}$, Tessier PA. Blockade of S100A8 and S100A9 suppresses neutrophil migration in response to lipopolysaccharide. J Immunol. 2003;171(5):2602-2609.

37. Ryckman C, Vandal K, Rouleau P, Talbot M, Tessier PA. Proinflammatory activities of S100: proteins S100A8, S100A9, and S100A8/A9 induce neutrophil chemotaxis and adhesion. J Immunol. 2003;170(6):3233-3242.

38. Endoh Y, Chung YM, Clark IA, Geczy CL, Hsu K. IL-10-dependent S100A8 gene induction in monocytes/macrophages by double-stranded RNA. JImmunol. 2009;182(4):2258-2268.

39. Nacken W, Lekstrom-Himes JA, Sorg C, Manitz MP. Molecular analysis of the mouse S100A9 gene and evidence that the myeloid specific transcription factor C/EBPepsilon is not required for the regulation of the S100A9/A8 gene expression in neutrophils. J Cell Biochem. 2001;80(4):606-616.

40. Kuwayama A, Kuruto R, Horie N, Takeishi K, Nozawa R. Appearance of nuclear factors that interact with genes for myeloid calcium binding proteins (MRP-8 and MRP-14) in differentiated HL-60 cells. Blood. 1993;81(11):3116-3121.

41. Clausen BE, Burkhardt C, Reith W, Renkawitz $\mathrm{R}$, Förster I. Conditional gene targeting in macrophages and granulocytes using LysMcre mice. Transgenic Res. 1999;8(4):265-277.

42. Dong X, Bachman LA, Miller MN, Nath KA, Griffin MD. Dendritic cells facilitate accumulation of IL-17 T cells in the kidney following acute renal obstruction. Kidney Int. 2008;74(10):1294-1309.

43. Heymann F, et al. Kidney dendritic cell activation is required for progression of renal disease in a mouse model of glomerular injury. J Clin Invest. 2009;119(5):1286-1297.

44. Geissmann F, Gordon S, Hume DA, Mowat AM, Randolph GJ. Unravelling mononuclear phagocyte heterogeneity. Nat Rev Immunol. 2010;10(6):453-460.

45. Varol C, et al. Intestinal lamina propria dendritic cell subsets have different origin and functions. Immunity. 2009;31(3):502-512.

46. Schulz O, et al. Intestinal CD103+, but not CX3CR1+, antigen sampling cells migrate in lymph and serve classical dendritic cell functions. J Exp Med. 2009;206(13):3101-3114.

47. Ginhoux F, et al. The origin and development of nonlymphoid tissue CD103+ DCs. J Exp Med. 2009;206(13):3115-3130.

48. Nacken W, Roth J, Sorg C, Kerkhoff C. S100A9/ S100A8: myeloid representatives of the S100 protein family as prominent players in innate immunity. Microsc Res Tech. 2003;60(6):569-580.

49. Gebhardt C, Németh J, Angel P, Hess J. S100A8 and S100A9 in inflammation and cancer. Biochem Pharmacol. 2006;72(11):1622-1631.

50. Quinlan MR, Docherty NG, Watson RWG, Fitzpatrick JM. Exploring mechanisms involved in renal tubular sensing of mechanical stretch following ureteric obstruction. Am J Physiol Renal Physiol. 2008;295(1):F1-F11.

51. Jaalouk DE, Lammerding J. Mechanotransduction gone awry. Nat Rev Mol Cell Biol. 2009;10(1):63-73.

52. Oishi Y, et al. Regulatory polymorphism in transcription factor KLF5 at the MEF2 element alters the response to angiotensin II and is associated with human hypertension. FASEB J. 2010; 24(6):1780-1788.

53. Ophascharoensuk V, et al. Obstructive uropathy in the mouse: role of osteopontin in interstitial fibrosis and apoptosis. Kidney Int. 1999;56(2):571-580.

54. Vielhauer V, Anders HJ, Perez de Lema G, Luckow B, Schlondorff D, Mack M. Phenotyping renal leukocyte subsets by four-color flow cytometry: characterization of chemokine receptor expression. Nephron Exp Nephrol. 2003;93(2):e63. 